\title{
Tidal variations in the Sundarbans Estuarine System, India
}

\author{
Meenakshi Chatterjee ${ }^{1,2, *}$, D Shankar ${ }^{3}$, G K Sen ${ }^{2}$, P Sanyal ${ }^{2}$, D Sundar ${ }^{3}$, \\ G S Michael ${ }^{3}$, Abhisek Chatterjee ${ }^{3}, \mathrm{P}_{\mathrm{Amol}^{3}}$, Debabrata Mukherjee ${ }^{2}$, \\ K Suprit ${ }^{3}$, A Mukherjee ${ }^{3}$, V Vijith ${ }^{3}$, Siddhartha Chatterjee ${ }^{2,3}$, Anwesha Basu ${ }^{2}$, \\ Madhumita Das ${ }^{2}$, Saranya Chakraborti ${ }^{2}$, Aravind Kalla ${ }^{3}$, SurJa Kanta Misra ${ }^{2}$, \\ Soumya Mukhopadhyay ${ }^{2,3}$, Gopal Mandal ${ }^{2}$ and Kankan Sarkar ${ }^{2,3}$ \\ ${ }^{1}$ Basanti Devi College, Kolkata 700 029, India. \\ ${ }^{2}$ School of Oceanographic Studies, Jadavpur University, Kolkata 700 032, India. \\ ${ }^{3}$ CSIR - National Institute of Oceanography, Dona Paula, Goa 403 004, India. \\ *Corresponding author. e-mail: meenakshi.chatterjee11@gmail.com
}

Situated in the eastern coastal state of West Bengal, the Sundarbans Estuarine System (SES) is India's largest monsoonal, macro-tidal delta-front estuarine system. It comprises the southernmost part of the Indian portion of the Ganga-Brahmaputra delta bordering the Bay of Bengal. The Sundarbans Estuarine Programme (SEP), conducted during 18-21 March 2011 (the Equinoctial Spring Phase), was the first comprehensive observational programme undertaken for the systematic monitoring of the tides within the SES. The 30 observation stations, spread over more than $3600 \mathrm{~km}^{2}$, covered the seven inner estuaries of the SES (the Saptamukhi, Thakuran, Matla, Bidya, Gomdi, Harinbhanga, and Raimangal) and represented a wide range of estuarine and environmental conditions. At all stations, tidal water levels (every 15 minutes), salinity, water and air temperatures (hourly) were measured over the six tidal cycles. We report the observed spatio-temporal variations of the tidal water level. The predominantly semi-diurnal tides were observed to amplify northwards along each estuary, with the highest amplification observed at Canning, situated about $98 \mathrm{~km}$ north of the seaface on the Matla. The first definite sign of decay of the tide was observed only at Sahebkhali on the Raimangal, $108 \mathrm{~km}$ north of the seaface. The degree and rates of amplification of the tide over the various estuarine stretches were not uniform and followed a complex pattern. A least-squares harmonic analysis of the data performed with eight constituent bands showed that the amplitude of the semi-diurnal band was an order of magnitude higher than that of the other bands and it doubled from mouth to head. The diurnal band showed no such amplification, but the amplitude of the 6-hourly and 4-hourly bands increased headward by a factor of over 4 . Tide curves for several stations displayed a tendency for the formation of double peaks at both high water (HW) and low water $(\mathrm{LW})$. One reason for these double-peaks was the HW/LW stands of the tide observed at these stations. During a stand, the water level changes imperceptibly around high tide and low tide. The existence of a stand at most locations is a key new finding of the SEP. We present an objective criterion for identifying if a stand occurs at a station and show that the water level changed imperceptibly over durations ranging from 30 minutes to 2 hours during the tidal stands in the SES. The tidal duration asymmetry observed at all stations was modified by the stand. Flow-dominant asymmetry was observed at most locations, with ebb-dominant asymmetry being observed at a few locations over some tidal cycles. The tidal asymmetry and stand have implications for human activity in the Sundarbans.

Keywords. Estuaries; sundarbans; stand of the tide; platform tide; Hoogly; oceanography. 
The longer persistence of the high water level around high tide implies that a storm surge is more likely to coincide with the high tide, leading to a greater chance of destruction. Since the stands are associated with an amplification of the 4-hourly and 6-hourly constituents, storm surges that have a similar period are also likely to amplify more during their passage through the SES.

\section{Introduction}

The largest delta in the world, formed by the distributaries of the rivers Ganga and Brahmaputra (Seidensticker and Hai 1983; UNEP WCMC 1987; Papa et al. 2010), is shared by Bangladesh and India (figure 1). On its west, the delta is bordered by river Hoogly (also Hooghly, Hugli) and on its east by river Meghna (figure 1). The Bay of Bengal forms the southern boundary of the delta, which includes in its southern fringes the dense natural mangrove forests, the Sundarbans. The Indian part of the Sundarbans delta is about $40 \%$ of the total area. In this paper, we refer to this region lying between $21.25^{\circ}-22.5^{\circ} \mathrm{N}$ and $88.25^{\circ}-89.5^{\circ} \mathrm{E}$ as the Sundarbans Estuarine System (hereafter called SES).

The SES is the largest monsoonal, macro-tidal, delta-front, estuarine system in India and the most complex of the 100-odd estuaries that exist along the Indian coast. Its $9630 \mathrm{~km}^{2}$ area is spread over the entire South 24 Parganas and the southern parts of the adjoining North 24 Parganas, the two southernmost districts of the state of West Bengal (figure 1). River Hoogly, the westernmost estuary of the SES, is the first deltaic offshoot of the Ganga. River Raimangal (figure 2) forms the eastern boundary of the SES. This trans-boundary river is a tributary of river Ichhamati, an easterly distributary of the Ganga situated in the North 24

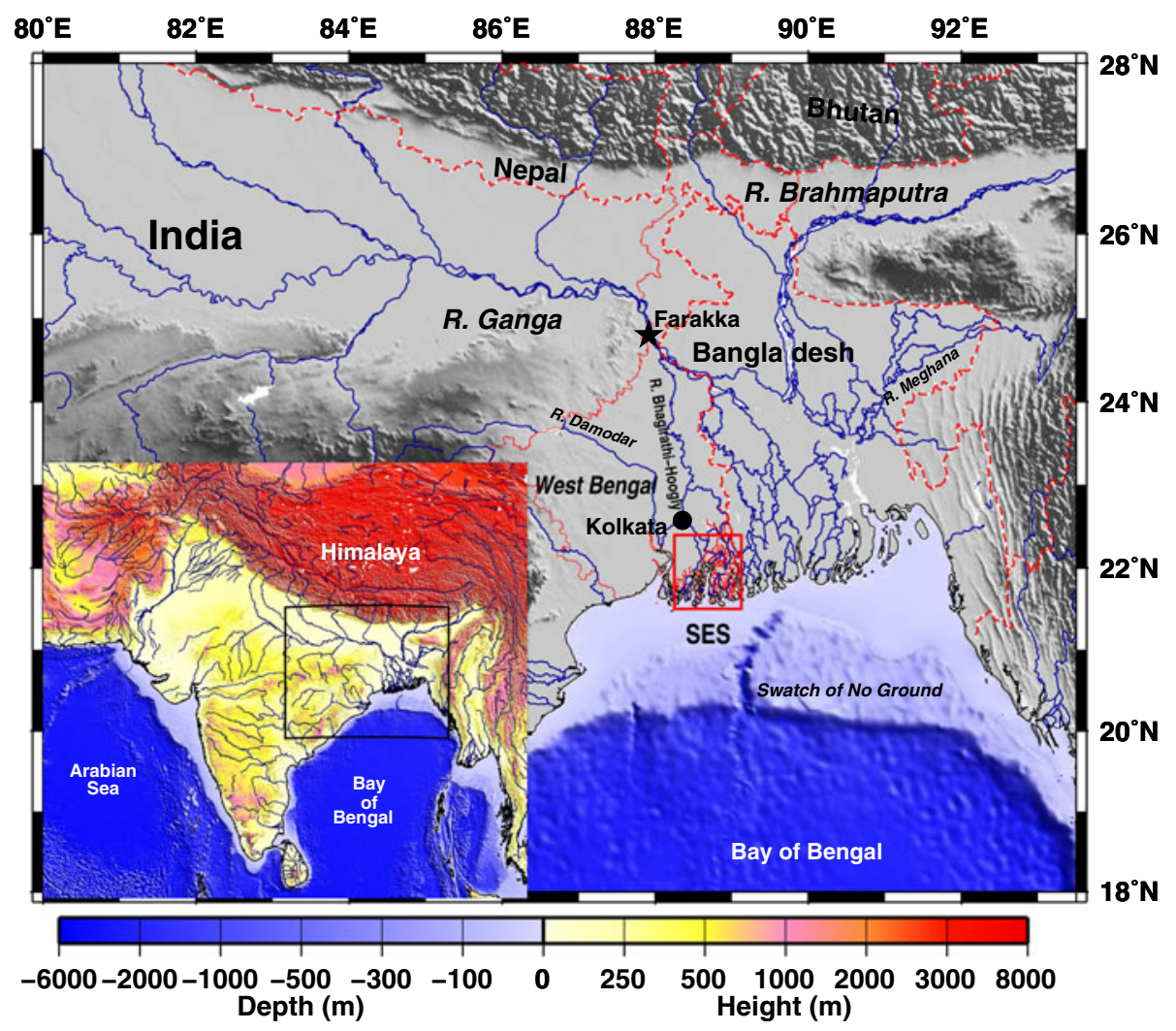

Figure 1. The physical setting of the Ganga-Brahmaputra river system and the delta system. The inset shows topographic and bathymetric details of the entire Indian subcontinent (the black rectangle marks the region plotted) with the major rivers (in blue), the Himalayas, the Arabian Sea and the Bay of Bengal. Topography and bathymetry data are from ETOPO1 (Amante and Eakins 2009); the colour scale for both maps is at the bottom of the figure. In the larger map, only the ocean bathymetry is plotted to scale, with only a three-step grayscale shading being used to indicate the land topography. The Farakka Barrage is located on the Ganga just upstream of the international border (red and white dashed curve) between India and Bangladesh. Note the 'Swatch of No Ground' in the Bay. The region shown in figure 2 is marked by the red box and consists of the South and North 24 Parganas districts in West Bengal within which the SES (excluding river Hoogly) is located. 


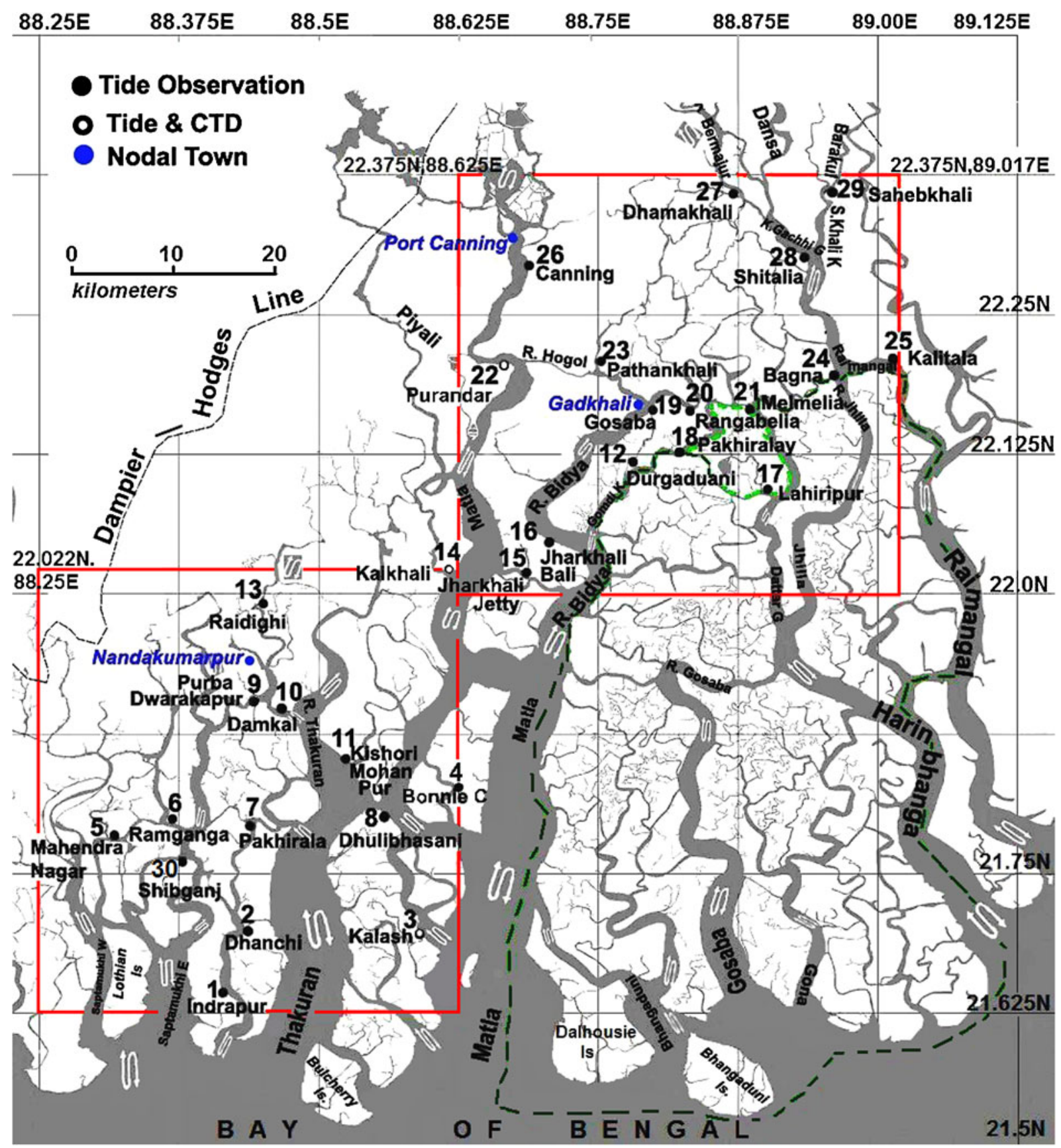

Figure 2. The Sundarbans Estuarine System (SES). Bordered in red is the area covered by the SEP. It consists of Sector 1 in the southwestern part and Sector 2 in the northeastern part. Names and numbers of the observation stations are shown. Dotted lines indicate the Sundarbans National Park and Tiger Reserve and the Buffer Zones (in green), and the DampierHodges Line (in blue). The map was prepared by digitizing the 1967-1969 toposheets (1:50,000 scale) of the Survey of India. The symbols (an ' $\mathrm{S}$ ' with arrows on either end) indicating the presence of the tide were filled in from these toposheets and the more recent map (1:250,000 scale; NATMO 2000) of the South 24 Parganas. This NATMO map was based on the SOI (1967-1969) toposheets, aerial photographs, IRS satellite imagery, and field surveys.

Parganas. The northern limit of the Sundarbans and the SES is defined by the Dampier-Hodges Line (figure 2), an imaginary line that is based on a survey conducted during 1829-1832.

The principal estuaries of the SES lying east of the Hoogly are the north-south flowing rivers: the Saptamukhi, Thakuran, Matla, Bidya, Gomdi (often called the Gomdi Khaal or the Gomor), Gosaba, Gona, Harinbhanga and Raimangal (figure 2). Interconnecting these estuaries and forming the complex estuarine network are numerous west-east flowing channels, canals and creeks. Some of these interlinking channels are wide and strong enough to be considered as estuaries by themselves. Others, 
especially those east of the Matla, still remain unexplored and unnamed.

All the principal estuaries in the SES (figure 2) are funnel-shaped and have very wide mouths. The approximate lengths of the main estuaries, locations about which their mouths are centred at their confluences with the Bay of Bengal, and the approximate widths at the mouths are listed in table 1. The Bidya and the Gomdi fall into the Matla around $21.917^{\circ} \mathrm{N}, 88.667^{\circ} \mathrm{E}$ and $22.069^{\circ} \mathrm{N}, 88.747^{\circ} \mathrm{E}$, respectively. Widths converge rapidly northwards after short and wide southern stretches. Except in the vicinity of the seaface, the estuaries follow meandering courses with sharp bends. This meandering is most noticeable on the Matla, the longest estuary. At the seaface, the width of its mouth is greater than $26 \mathrm{~km}$. It swings sharply to the west near its confluence with the Bidya (about $35 \mathrm{~km}$ due north of the seaface), after which the estuarine channel converges rapidly. At Port Canning $\left(22.317^{\circ} \mathrm{N}, 88.65^{\circ} \mathrm{E}\right.$; figure 2$)$, about $98 \mathrm{~km}$ north of the seaface, the width is less than $1 \mathrm{~km}$. As one moves eastward from the Matla, the interconnections become so complicated that they are difficult to identify as belonging to a particular estuary.

Both the Hoogly and the Raimangal still carry the freshwater discharge of the Ganga into the Bay of Bengal throughout the year, with the leanperiod freshwater flow through the Hoogly augmented by the diversion of regulated amounts of the Gangetic main flow through the Farakka Barrage (figures 1 and A1). All former distributaries of the Ganga, the inner estuaries of the SES lying between the Hoogly and the Raimangal are at present saline, tidal rivers. Geological changes during the 16th century caused the main flow of the Ganga to shift progressively eastward, resulting in the complete severance of these inner estuaries from the Gangetic freshwater flow at their upstream heads (Seidensticker and Hai 1983; UNEP WCMC 1987; Parua 2010).

The estuarine character of the inner estuaries in the SES is now maintained by the semi-diurnal tides at their mouths and the freshwater received as local runoff. The major portion of the local runoff comes annually from the summer monsoon rainfall, ranging between 1500 and $2500 \mathrm{~mm} /$ year (Attri and Tyagi 2010) in this region and from the floods resulting from the freshwater accumulation in the upstream parts of the Ganga during the monsoons. Considerable precipitation is also received from the frequent pre-monsoon (March-June) and post-monsoon (October-February) depressions and cyclones that form and move in from the Bay of Bengal. Precipitation accompanying the frequently occurring pre-monsoon thunderstorms during March-May (known as Nor'westers or, locally, Kaal Baisakhi) is another source of freshwater runoff during the dry season (Attri and Tyagi 2010). It is possible that some amounts of vertical and lateral seepage of freshwater from underground aquifers may also occur.

Several comprehensive reviews of the Sundarbans and its estuarine network are available in Seidensticker and Hai (1983), Sanyal (1983), UNEP WCMC (1987), De (1990), Bannerjee (1998), Guha Bakshi et al. (1999), Mandal (2003), NGIA (2005) and Sarkar (2011). The brief overview of the region given below is based on these reviews.

The estuarine network has divided the terrain into 102 islands: 52 of these, covering an area of $5336 \mathrm{~km}^{2}$, are currently inhabited by a population of over 4 million. Reclaimed from the forests since the 18th century, these islands are mostly situated in the northern 'stable' part of the Gangetic delta. Being only $0-3 \mathrm{~m}$ above the mean sea level, most settled areas are protected

Table 1. Approximate lengths, location of the mouths and width at the mouths of the main estuaries in the Sundarbans Estuarine System. Estuary codes used in the text are given in brackets. Dimensions are approximated by rounding off.

\begin{tabular}{|c|c|c|c|c|}
\hline & \multirow[b]{2}{*}{$\begin{array}{l}\text { Length } \\
(\mathrm{km})\end{array}$} & \multicolumn{2}{|c|}{ Location of mouth } & \multirow[b]{2}{*}{$\begin{array}{c}\text { Width } \\
(\mathrm{km})\end{array}$} \\
\hline & & $\begin{array}{l}\text { Latitude } \\
\qquad\left({ }^{\circ} \mathrm{N}\right)\end{array}$ & $\begin{array}{l}\text { Longitude } \\
\qquad\left({ }^{\circ} \mathrm{E}\right)\end{array}$ & \\
\hline Saptamukhi (S) & & 21.604 & 88.352 & 10.0 \\
\hline Saptamukhi West Gulley (SWG) & 41.0 & & & \\
\hline Saptamukhi East Gulley (SEG) & 64.0 & & & \\
\hline Thakuran (T) & 62.0 & 21.658 & 88.492 & 10.0 \\
\hline Matla (M) & 125.0 & 21.603 & 88.655 & 26.0 \\
\hline Harinbhanga $(\mathrm{H})$ & 79.0 & 21.718 & 89.081 & 6.0 \\
\hline Raimangal (R) & 114.0 & 21.781 & 89.138 & 8.0 \\
\hline Bidya $(\mathrm{B})$ & 83.5 & 21.920 & 88.670 & 4.5 \\
\hline Gomdi (G) (Gomdi Khaal/Gomor) & 67.0 & 22.070 & 88.750 & 1.0 \\
\hline
\end{tabular}


by embankments. The nodal towns (figure 2) situated in the northern parts of the SES, such as Raidighi $\left(21.994^{\circ} \mathrm{N}, 88.447^{\circ} \mathrm{E}\right)$ which is also an observation station, Nandakumarpur $\left(21.937^{\circ} \mathrm{N}\right.$, $\left.88.218^{\circ} \mathrm{E}\right)$, Port Canning and Gadkhali $\left(22.168^{\circ} \mathrm{N}\right.$, $88.788^{\circ} \mathrm{E}$ ), are approximately $130-150 \mathrm{~km}$ away from the state capital Kolkata $\left(22.57^{\circ} \mathrm{N}, 88.37^{\circ} \mathrm{E}\right)$, which lies to the northwest of the region (figure 1).

Seventy percent of the terrain within the SES consists of water bodies, intertidal mudflats and creeks, saline swamps, sandy shoals, and dense, impenetrable forests. Inundation of these areas during high tide effectively increases the surface area of the estuarine channels. The submerged shoals, especially those at the mouth of the estuaries, change their orientations with every tidal cycle and are a hazard to navigation. The main estuaries and their network of naturally connected channels are mostly shallow, but navigable. They are heavily used for local transportation, tourism, and as economically viable shipping routes for the transport of goods between the ports of Kolkata (figures 1 and $\mathrm{A} 1)$ and Haldia $\left(22.017^{\circ} \mathrm{N}, 88.083^{\circ} \mathrm{E}\right.$; figure A1), to the northeastern states of India (IWAI 2011).

Within the SES, tidal influences underlie all the basic physical processes operating in the region. Indeed, the tides are so woven into the fabric of life in the Sundarbans that it is referred to as the Bhatir Desh or 'tidal country' (Beveridge 1897; Roy 1949b; Ghosh 2004; Chakrabarti 2009). This influence of the tides is more evident in the very dynamic 'active delta' in the relatively pristine southern part of the SES. Consisting of the 48 remaining islands, it occupies an area of $4264 \mathrm{~km}^{2}$. Here, the still continuing process of delta-building manifests itself through erosion and accretion processes that operate continuously under the action of the semi-diurnal tides, high winds, wave action, shifting sediment loads, and other natural processes. The delicately balanced conditions existing in the numerous, unique and fragile ecosystems change almost daily under tidal influences.

The SES forms the most important spawning zones and nursery for shrimps, prawns and a wide variety of fish and crustaceans, not only locally, but for the entire east coast of India. It also provides major pathways for nutrient recycling and acts as a natural filter for pollutants released from the human settlements and industrial belts in its northern reaches. Strict conservation measures initiated during the 1970s by the governments of India and West Bengal have resulted in the entire 'active' delta area being declared as protected Reserved Forests. Located in the southeastern sector of the SES is the Sundarbans National Park and Tiger Reserve $\left(21.545^{\circ}-21.929^{\circ} \mathrm{N}\right.$, $88.691^{\circ}-89.103^{\circ} \mathrm{E}$; area $2585 \mathrm{~km}^{2}$ ), with a core area of about $1330 \mathrm{~km}^{2}$ (figure 2). It was declared a UNESCO World Heritage Site in 1987, while the entire SES was declared a Global Biosphere Reserve in 2001. The astounding biodiversity of the region is well known. It is all the more remarkable owing to its being the only habitat, at present, of several globally endangered species of flora and fauna, chief amongst which are the Sundari tree, which gives the Sundarbans its name, and the Royal Bengal Tiger.

The strategic location of the Sundarbans at the head of the Bay of Bengal has also made it a natural protective barrier for the densely populated city of Kolkata to its north: the mangrove barriers are the first to absorb and reduce the direct impact of the cyclonic storms and accompanying surges moving in from the Bay of Bengal. Though they protect Kolkata from the impact of these surges, the Sundarbans themselves are vulnerable to them. This vulnerability was underscored when surges of $2-$ $3 \mathrm{~m}$ due to Cyclone Aila swept through the region on 25 May 2009, breaching more than $400 \mathrm{~km}$ of embankments and taking a huge toll: the entire Sundarbans biosphere reserve was inundated with 2-6 $\mathrm{m}$ of water for several days. Official estimates record 70 people dead and about 8000 missing. Dozens of tigers (out of the existing 256 or so), crocodiles and deer were swept away by the surge. In all, about 2.5 million people were affected by the cyclone and the damage caused was estimated at about Rs 1500 crores (about 550 million USD) (India Meteorological Department 2009; Wikipedia 2012). While it may be tough to protect infrastructure, an ability to predict the surge can help to save lives because the surge takes time to propagate through the long estuarine channels to reach the more thickly populated northern parts. Any progress in understanding and predicting the propagation of a storm surge through the SES is, however, contingent on the ability to predict the tide, making it critical to study the tides first.

In the overall Indian context, the first systematic observational programme on tides in estuaries was initiated by the CSIR National Institute of Oceanography (CSIR-NIO) in 1993 for investigating tidal propagation in the Mandovi-Zuari Estuarine Network on the west coast of India (Shetye et al. 1995, 1996, 2007; Sundar and Shetye 2005; Vijith et al. 2009). A similar ongoing programme for the Gautami branch of the Godavari estuary on the Indian east coast has been carried out by CSIR-NIO for the last few years (Bouillon et al. 2003; Sarma et al. 2009, 2010, 2011; Acharyya et al. 2012). The other estuarine system that has received attention is the Kochi (Cochin) Backwaters (Quasim and Gopinathan 1969; Dinesh Kumar 2001; Srinivas et al. 2003; Martin et al. 2008; Joseph et al. 2009). Of these, the Mandovi-Zuari 
and Godavari are examples of estuaries with a single channel; estuaries of this type are by far the most numerous in India. Kochi Backwaters is an example of an estuarine lake with one or two openings to the sea. The Sundarbans form a deltafront estuarine complex; other such deltas in India are much smaller, making the SES an important system to be studied.

A survey of the available literature reveals that most studies in the SES are on the Hoogly. Several studies exist on its hydrodynamical, morphological, chemical and biological characteristics; a brief summary of the existing knowledge of the Hoogly estuary is given in Appendix 1. In contrast, the existing studies on the inner estuaries of the SES are sparse and have been conducted in a sporadic and highly localized manner. Most of these studies deal with the chemical and biological aspects of the Matla and the Saptamukhi; a brief summary of these studies is also provided in Appendix 1. To the best of our knowledge, there are no comprehensive observational studies of tidal propagation involving a network of stations located on each of the estuaries within the SES. The complexities of the network, the forbidding terrain, and the dangers associated with working in the region have no doubt contributed to this state of affairs.

The Survey of India (SOI) toposheets (SOI, 1967-1969 and 1977), based on surveys conducted during 1967-1968 and drawn on a scale of 1:50,000

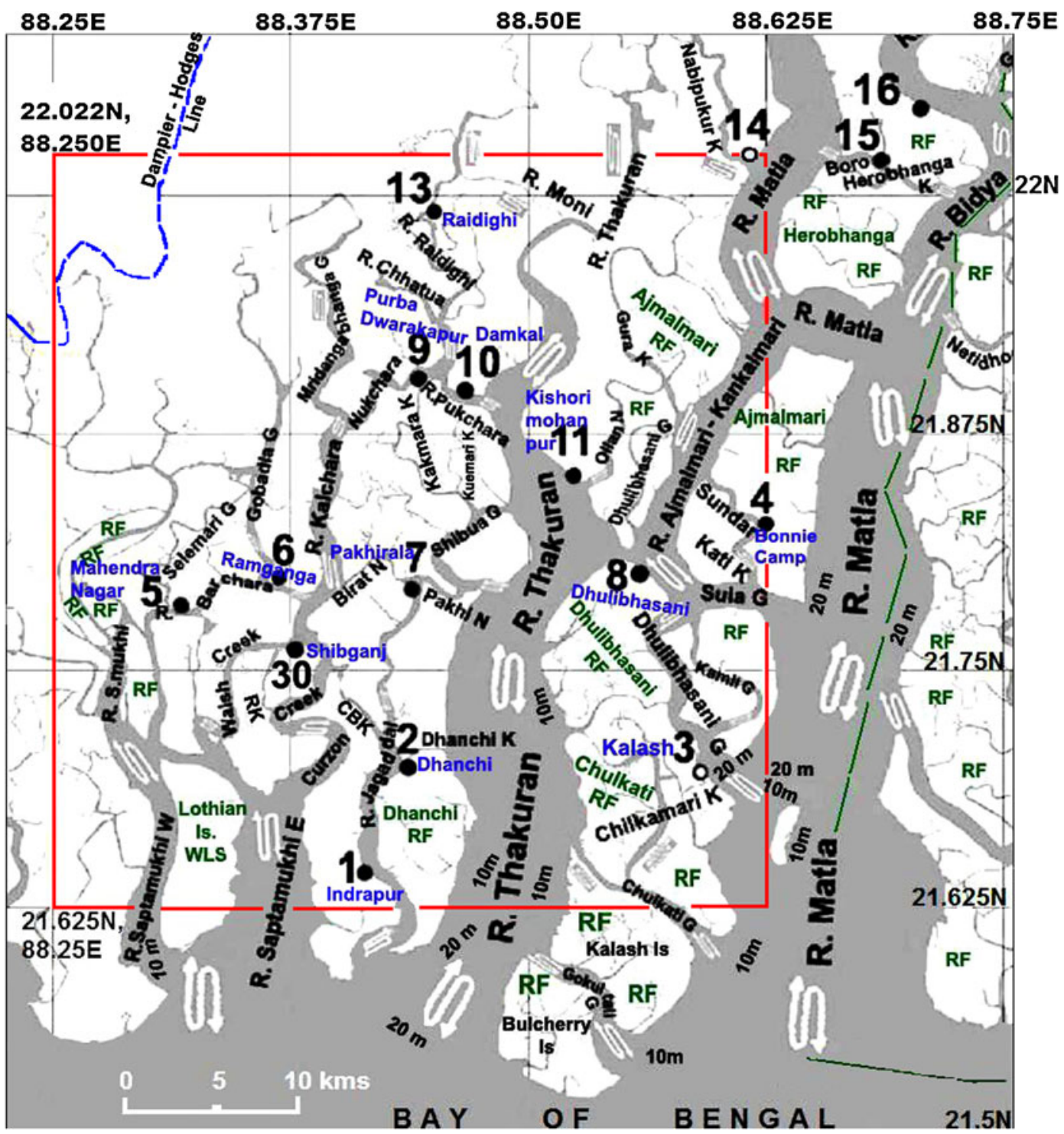

Figure 3. Sector 1 of the study area of the SEP enlarged from the map in figure 2. The depths near the mouths of the estuaries, names of interlinking channels, etc. were filled in from the SOI (1967-1969) toposheets and the NATMO (2000) map of the South 24 Parganas. Legends are same as in figure 2. Additional abbreviations are as follows: $\mathrm{R}=\mathrm{River}, \mathrm{K}=$ Khaal, $\mathrm{G}=$ Gaang, RF = Reserve Forest, WLS = Wild Life Sanctuary, RK = Rakshaskhali K, CBK = Chalta Bunia K. The unlabelled island on the Matla (between $21.625^{\circ}$ and $21.75^{\circ} \mathrm{N}$ ) is the Halliday Island WLS. 
indicate symbolically the extent of tidal incursion within the SES; these maps suggest that the tide exists throughout the length of the estuaries (figures 2-4). The symbols indicating the tidal incursions, the depths near the mouths of the estuaries, names of interlinking channels, etc. were filled in from these toposheets and a more recent but less detailed map of the South 24 Parganas published by NATMO (2000). This map, drawn on a 1:250,000 scale is based on the SOI toposheets, aerial photographs, satellite imagery and field surveys. Nevertheless, owing to the considerable land reclamation activity that has taken place in the SES since 1971, mostly for human settlement, construction of embankments, sluice gates and roads, locations on the map and even the state of the link channels needed to be actually verified. The development activity in the region since 1971 has included the construction of jetties, for which knowledge of the high-water level is necessary. Our knowledge of the tides in the SES is essentially limited to these two facts: the limits of tidal incursion and rough estimates of the level of high water at several locations.

It is also known that the tide at the mouth of the SES estuaries is predominantly semi-diurnal (Kyd 1829; Majumdar 1942; Chugh 1961; Murty and Henry 1983). A sketchy description exists in Majumdar (1942), of the manner in which the tide propagates from the Bay of Bengal towards the mouths of these estuaries. Similar descriptions regarding tidal propagation up the Matla exists in several sailing instructions (Anonymous 1865; NGIA 2005), dating as far back as 1865, when Port Canning was operational. According to Majumdar (1942), the semi-diurnal tides propagate along the deep central portion of the funnel-shaped Bay of Bengal (figure 1) and reach first the head of the 'Swatch of No Ground' $\left(21.083^{\circ} \mathrm{N}, 89.283^{\circ} \mathrm{E}\right)$, a deep submarine trench in the Bay almost in line

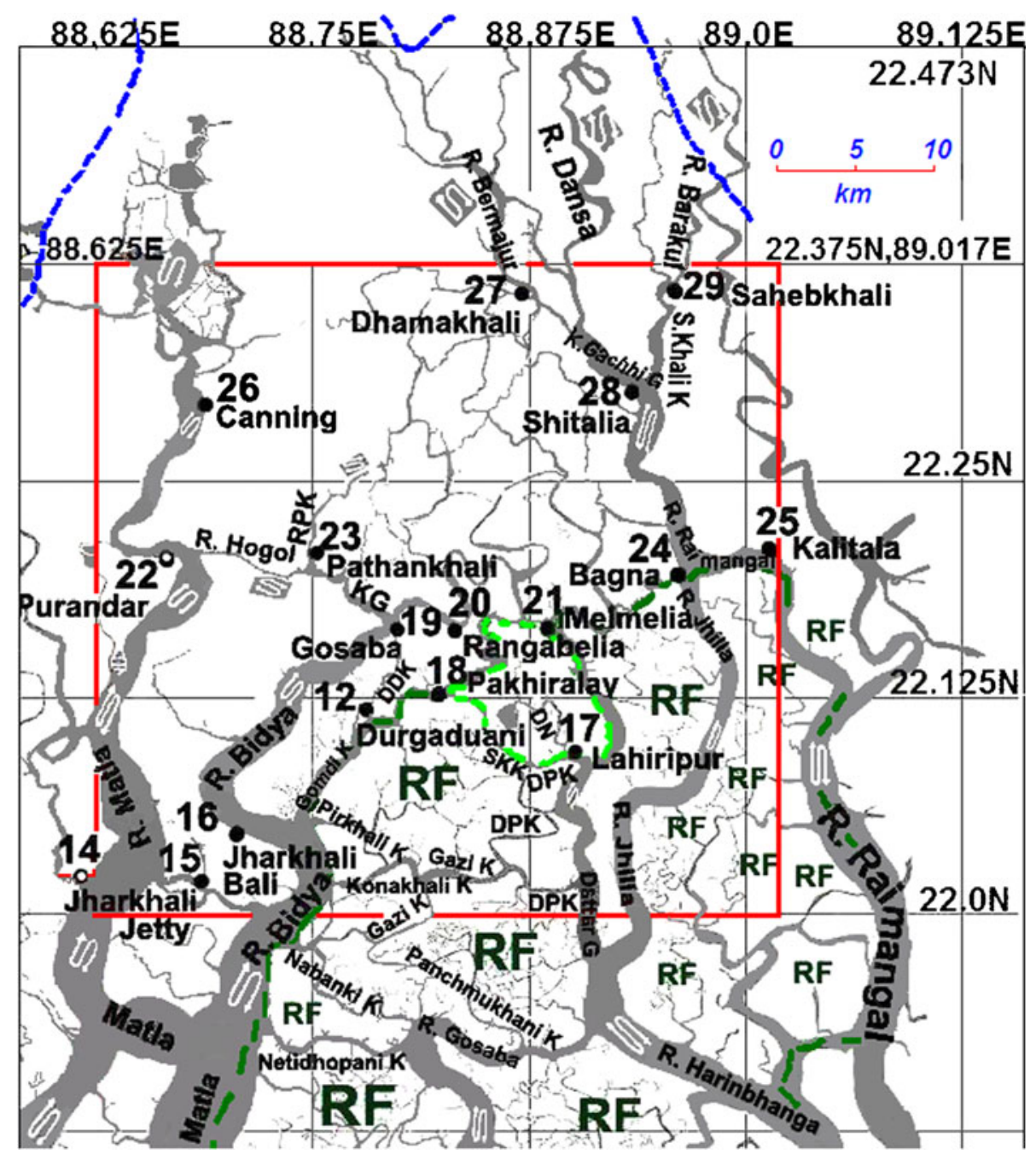

Figure 4. Sector 2 of the study area of the SEP enlarged from the map in figure 2. Legends and scale used are as in figure 3. Additional abbreviations are as follows: RPK $=$ R. Pathankhali, KG = Kartal Gaang, DDK = Durgaduani Khaal, SKK $=$ Sajnekhali Khaal, DN = Datta Nadi (River), DPK = Datta'r Passur Khaal, K Gachhi G = Kalagachhia Gaang. 
with the central part of the delta. It then travels along the delta face, bifurcating into an easterly and westerly branch. Owing to this bifurcation and the irregular seaward extension of the delta, the arrival of the tide is different at different points at the same latitude along the seaface.

Very little else is known about the tides in the SES. Thus, it is not known whether the tidal wave amplifies or decays as it propagates northwards along each estuarine channel, whether the patterns of amplification or decay are similar or different for each estuary, at what distance from the mouth does the tide begin to decay, what tidal constituents, other than the semi-diurnal, contribute significantly to the composition of the tidal wave, and whether these other constituents vary spatially. It is in order to answer these questions and to generate baseline data on the tides in the SES estuaries that the Sundarbans Estuarine Programme (SEP) was undertaken during 18-21 March 2011. The SEP aimed at providing a set of comprehensive and simultaneous measurements of tidal elevations, temperature and salinity at 30 locations situated on the inner estuaries of the region.

In this paper, we report the observed spatial and temporal variations of the tidal water levels. The plan of the paper is as follows. Section 2 contains a brief overview of the SEP, the area covered and the methodology followed in making the observations. Section 3 contains a description of the water-level data; it deals with the amplification or decay of the tide as it propagates upstream in the various estuaries and their interlinking channels. The tidal constituent bands that emerge from the harmonic analysis of the data and their characteristics are discussed in section 4 . In section 5 , we present an interesting tidal feature that was observed at several of the locations: the Tidal Stand or Platform Tide. We believe this to be the first time such a feature is being reported from an Indian estuary. The tidal duration asymmetry observed at all stations and its modification by the stand has also been discussed in this section. Finally, in section 6 , we present the main conclusions that can be drawn from the study.

\section{The Sundarbans Estuarine Programme (SEP)}

Following the precedent set in the Mandovi-Zuari estuarine system, it was decided to conduct the SEP during an Equinoctial Spring Phase of the lunar cycle in the dry period. Logistics and the time required for planning led to the 3-day observations being carried out during 18-21 March 2011. In this section, we present the rationale for choosing the observation stations and describe the methods used.

\subsection{Selection of observation stations}

Since the SOI toposheets (SOI, 1967-1969 and 1977) and local knowledge suggested that tides were experienced throughout the SES (figures 2-4), it was necessary to cover the entire region. Nevertheless, the number of stations had to be limited to about 30 in this network of channels, which range from the widest and longest estuary, the Matla, to the small interconnections, and spread over an area exceeding $9000 \mathrm{~km}^{2}$. The dearth of information from the SES and the huge area to be covered implied that several decisions had to be made on the basis of the meagre information available.

Making measurements in the eastern estuaries also required permissions from the Forest Department (Govt. of West Bengal) and the Border Security Force (for the region near the international border). The Sundarbans National Park and Tiger Reserve $\left(21.545^{\circ}-21.929^{\circ} \mathrm{N}, 88.691^{\circ}-\right.$ $89.103^{\circ} \mathrm{E}$ ) is easily recognizable in figures $2-4$ as the southeastern portion bordering the Bay of Bengal in which no observation stations are located. Entry to this area is highly restricted and permission could not be obtained from the Forest Department, restricting the observations in the eastern sector to the more populated northern part (Sector 2; figures 2 and 4). It was only in the more populated western sector (Sector 1; figures 2 and 3 ) that observations could be made from near the mouth to the upstream end. The observations were therefore confined to an area of about $3600 \mathrm{~km}^{2}$ (figure 2).

Another problem was that the available maps were outdated. The SOI surveys had been conducted during 1967-1968, before the influx of refugees in 1971 led to considerable reclamation of forest land for human settlement. These developments, which included construction of embankments, sluice gates and roads, implied that locations on the map, and even the state of the smaller link channels had to be verified by ground surveys, which were carried out during several reconnaissance trips made while planning for the SEP.

The major problem, once the region to be covered was cut to approximately $40 \%$ of the size of the SES, was presented by the terrain of the Sundarbans, which consists essentially of the mud deposited by the Gangetic distributaries and the mangrove forests that blanket the region. The settlements in the Sundarbans have been built on this foundation of soft mud, and boats are the only means of reaching most of them. Nandakumarpur $\left(21.937^{\circ} \mathrm{N}, 88.218^{\circ} \mathrm{E}\right.$; figure 2$)$ in Sector 1 


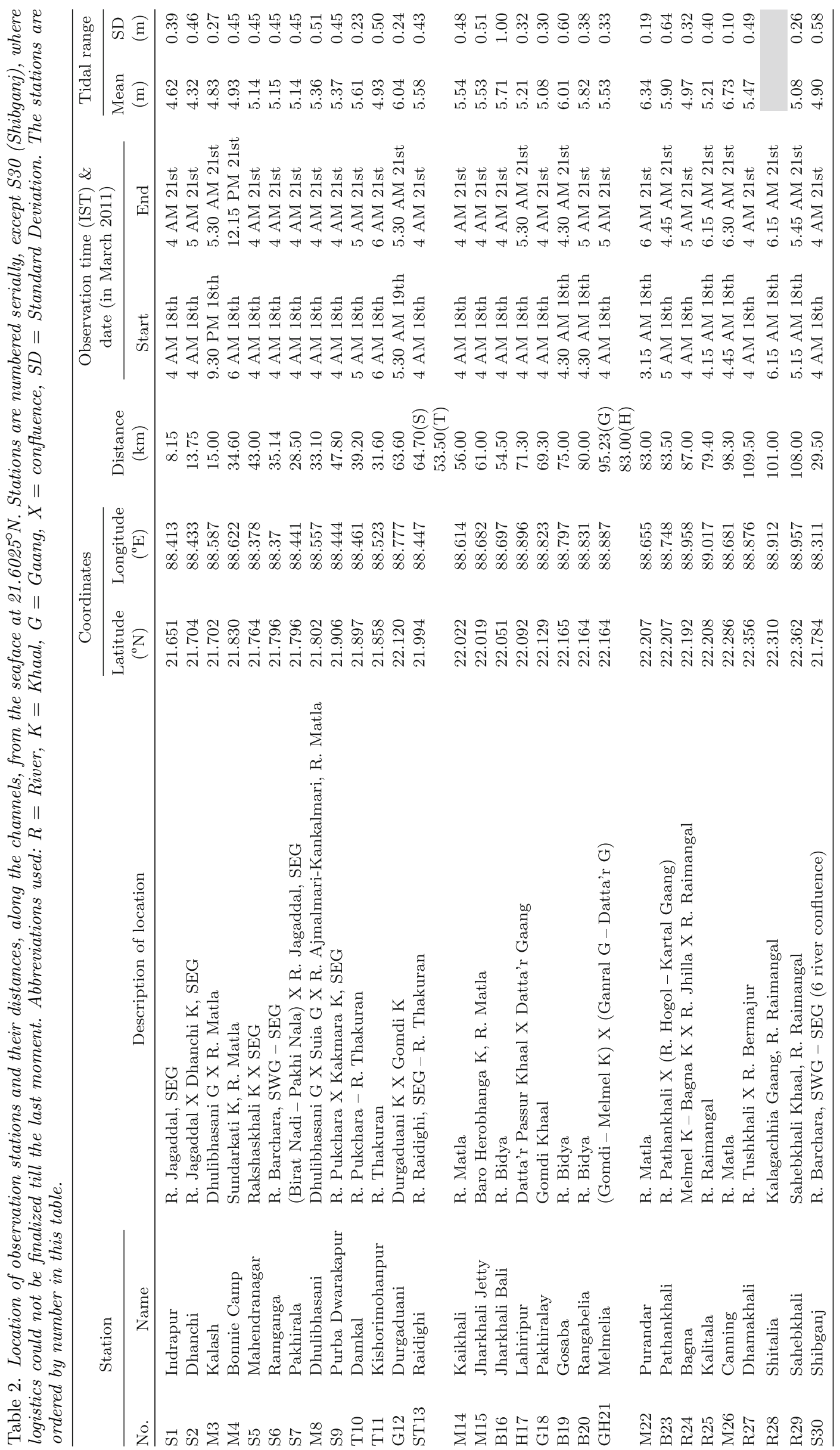


(about $110 \mathrm{~km}$ southeast of Kolkata) and Gadkhali $\left(22.168^{\circ} \mathrm{N}, 88.788^{\circ} \mathrm{E}\right.$; figure 2) in Sector 2 (about $130 \mathrm{~km}$ southeast of Kolkata) are the farthest nodal towns accessible by road from Kolkata. Mechanized boats are the only means of transport beyond these towns. Communication facilities are, however, excellent and mobile phones could be used throughout the SEP area. Therefore, in selecting the location of the observation stations, proximity to jetties and ferry landings was a major factor, but the measurement location was kept sufficiently far from the jetty to preclude any disturbance of the water level by the river traffic and disturbance to the traffic by the SEP. The Visual Tide Staff (VTS) or Tide Pole was the key instrument used for measuring the water level, and the chosen site had to be suitable for installing the VTS. The fabrication and deployment of the VTS is described briefly in Appendix 2.

Eventually, 30 stations were selected based on the above criteria: the stations had to cover the entire area of the SEP, jetties had to be available in the neighbourhood, and the location had to be suitable for erecting the VTS. Fourteen of these stations were in Sector $1\left(21.625^{\circ}-22.022^{\circ} \mathrm{N}\right.$, $88.250^{\circ}-88.625^{\circ} \mathrm{E}$; figure 3 ), which covered an area of approximately $1814 \mathrm{~km}^{2}$. The stations in this sector lay on the Saptamukhi, Thakuran, and the southern part of the Matla. The remaining 16 stations were in Sector $2\left(22.022^{\circ}-22.375^{\circ} \mathrm{N}, 88.625^{\circ}-\right.$ $89.017^{\circ} \mathrm{E}$; figure 4$)$, which covered an area of approximately $1800 \mathrm{~km}^{2}$. The stations in this sector lay on the northern part of the Matla and on the Bidya, Gomdi, Harinbhanga, and Raimangal. Since the southeastern part of the SES could not be surveyed, the southernmost (near the mouth) station was Indrapur on the Jagaddal, a distributary of the Saptamukhi, in Sector 1, and the northernmost station was Dhamakhali at the confluence of the rivers Tushkhali and Bermajur in Sector 2.

The mouth of the Matla being the southernmost, its latitude $\left(21.6025^{\circ} \mathrm{N}\right)$ has been taken to represent the seaface, from which the distance, along the channel, of all the 30 observation stations have been calculated. For each estuary, we use a code, which is simply the first alphabet of its name (table 1), to facilitate identification of the stations with the estuaries on which they are situated. The list of the 30 stations is given in table 2 . The stations have been named according to the estuary on which they are situated. For example, S30 indicates Shibganj, with the 'S' signifying its location on the Saptamukhi (figure 3). Two stations were located at the confluence of two estuaries and their names therefore include the code for both estuaries. These were Raidighi (ST13), which is located on both Saptamukhi and Thakuran (figure 3), and Melmelia (GH21), which is located on both Gomdi and Harinbhanga (figure 4).

A potential source of confusion is the tradition in the Sundarbans of giving different names to the same west-east (south-north) flowing channel after its confluence with a south-north (west-east) flowing channel. An example is given by the west-east flowing channels the Barchara-KalcharaNukchara-Pukchara; these names are used, respectively, for the channels to the east of the Saptamukhi West Gulley (SWG), between the SWG and the Saptamukhi East Gulley (SEG), and east of the SEG (figure 3). In such cases, we have used a hyphen, as indicated above, to separate the various names that the channel takes.

\subsection{Methodology}

The observations at all 30 stations were carried out from boats that were anchored for the duration of the SEP. Details of the observation procedures, including the problems encountered, are given in Appendix 2. Observations during the SEP started at 4 am (Indian Standard Time or IST) on 18 March 2011 and ended at 4 am on 21 March 2011. During this 72-hour period, simultaneous observations of the variables listed in table 3 were carried out at each of the 30 stations. In addition, hourly CTD (Conductivity-TemperatureDepth) casts were made at three locations on the Matla: M3 (Kalash), M14 (Kaikhali), and M22 (Purandar). This paper is restricted to the water level; the salinity data will form the subject of a future paper.

The observations during the SEP included the Full Moon phase of the Equinoctial Spring, with the Full Moon occurring at 11 pm on 19 March. This period was rather unique in that 18 March was

Table 3. Variables observed during the Sundarbans Estuarine Programme.

\begin{tabular}{lll}
\hline Variable & $\begin{array}{c}\text { Frequency of } \\
\text { observations }\end{array}$ & \multicolumn{1}{c}{ Instrument used } \\
\hline Water level & 15 minutes & Tide pole \\
Salinity & 1 hour & Sampling bottles and Autosal \\
Water temperature & 1 hour & Thermometer \\
Air temperature (dry and wet bulb) & 1 hour & Thermometer \\
\hline
\end{tabular}


Table 4. Missed observations.

\begin{tabular}{|c|c|c|c|c|c|c|}
\hline \multicolumn{2}{|c|}{ Station } & \multicolumn{2}{|c|}{$\begin{array}{c}\text { Missed } \\
\text { observations }\end{array}$} & \multicolumn{2}{|c|}{$\begin{array}{l}\text { Total number of } \\
\text { observations }\end{array}$} & \multirow{2}{*}{$\begin{array}{c}\% \text { of } \\
\text { observations } \\
\text { missed }\end{array}$} \\
\hline Number & Name & Number & Hours & Number & Hours & \\
\hline S1 & Indrapur & 18 & 2 & 289 & 72 & 6.2 \\
\hline $\mathrm{S} 2$ & Dhanchi & 6 & 1.5 & 294 & 73 & 2 \\
\hline M3 & Kalash & 38 & 9.5 & 225 & 56 & 17 \\
\hline M4 & Bonnie Camp & 7 & 1.75 & 218 & 54.5 & 3.2 \\
\hline S30 & Shibganj & 24 & 6 & 289 & 72 & 8.3 \\
\hline ST13 & Raidighi & 39 & 9.75 & 289 & 72 & 13.5 \\
\hline G18 & Pakhiralay & 14 & 3.5 & 289 & 72 & 4.8 \\
\hline B19 & Gosaba & 6 & 1.5 & 289 & 72 & 2 \\
\hline M22 & Purandar & 5 & 1.25 & 299 & 74.5 & 1.7 \\
\hline $\mathrm{R} 24$ & Bagna & 6 & 1.5 & 293 & 73 & 2 \\
\hline M26 & Canning & 83 & 20.75 & 288 & 71.75 & 28.8 \\
\hline $\mathrm{R} 28$ & Shitalia & 111 & 27.75 & 289 & 72 & 38.4 \\
\hline
\end{tabular}

the day of maximum semi-diurnal tidal forcing: On this day, zero solar declination and lunar perigee occurred almost simultaneously with zero lunar declination, resulting in the semi-diurnal tidal amplitude being 1.88 times the equilibrium amplitude. Amplitudes of this magnitude or greater occurred in 1980, 1993, 1997, 1998, and 2002, but will not occur again until 2028 (Pugh 1987).

The weather during the 72-hour period remained clear and sunny with occasional cloudiness. A strong southerly-southwesterly wind blew continuously. Hourly METAR records of wind speeds at Kolkata airport (nearly $150 \mathrm{~km}$ inland and northwest of the SES) showed wind speeds between 5 and $7.5 \mathrm{~m} / \mathrm{s}$ throughout the observations. Surface pressure was between 1004 and $1005 \mathrm{hPa}$ at $6 \mathrm{~m}$ (the mean sea level at Kolkata). The interaction of the southerly wind with the southward ebb tide resulted in turbulent conditions: high waves with continuous wave breaking were seen especially in the main south-north flowing estuaries (see Appendix 2). At a few places, namely, S1 (Indrapur), S2 (Dhanchi), M3 (Kalash), and M22 (Purandar), the originally planned locations had to be shifted to avoid the direct impact of the strong wind and waves. At Indrapur, the shift was from the SEG to the Jagaddal, and at Kalash, the location was shifted some distance into the Dhulibhasani Gaang, a prominent channel to the west of the Matla, where the conditions were more conducive to anchor a boat than in the main channel.

At 12 of the stations, gaps in the observations exist; details of these gaps have been provided in Appendix 2. At six of these stations, the missing data constitute $<5 \%$ of the total observations; at four of the other six, they constitute between
5-20\% (table 4). The maximum, $38.4 \%$ of the observations, was missed at Station R28 (Shitalia). The minimum and maximum lengths of continuous observations were 48 hours (at M26, Canning and G12, Durgaduani) and 75 hours (at S7, Pakhirala).

To the best of our knowledge, the data collected during the SEP being reported here are the first of its kind from this region. Coming from the extensive network of stations spread nearly all over the SES, they also represent a wide range of estuarine and environmental conditions. The water-level data are presented in the following section.

\section{Tides in the Sundarbans Estuarine System}

Altogether, six low and high tides occurred during the 72-hour observation period. When observations started at 4 am on 18 March, the first Low Water (LW0) had already passed and the majority of the stations failed to observe it. A few of the extreme northern and northeastern stations could, however, capture LW0, which occurred between 4 and 5 am at these stations. Likewise, LW6, which occurred between 5.15 and 5.30 am on 21 March, could be observed only at some of the southern stations. The timings of the high water (HW) and LW for all stations are listed in tables 5 and 6 .

The dominantly semi-diurnal nature of the tides in each of the seven estuaries of the SES is captured distinctly in the observed water level variations (figure 5). Figure 6 shows the range of the tide as a function of the along-channel distance from the seaface. Tidal ranges at any location are defined as the differences between successive HW and LW 
Table 5. Times (IST) of reaching High Water (HW) and corresponding HW levels ( $m$ ). Grey cells indicate missed observations. All times are in IST.

\begin{tabular}{|c|c|c|c|c|c|c|c|c|c|c|c|c|}
\hline \multirow{2}{*}{$\begin{array}{l}\text { Station } \\
\text { number }\end{array}$} & \multicolumn{2}{|c|}{ HW1: 18 March } & \multicolumn{2}{|c|}{ HW2: 18 March } & \multicolumn{2}{|c|}{ HW3: 19 March } & \multicolumn{2}{|c|}{ HW4: 19 March } & \multicolumn{2}{|c|}{ HW5: 20 March } & \multicolumn{2}{|c|}{ HW6: 20 March } \\
\hline & $\mathrm{AM}$ & HWL1 & $\mathrm{PM}$ & HWL2 & $\mathrm{AM}$ & HWL3 & PM & HWL4 & $\mathrm{AM}$ & HWL5 & $\mathrm{PM}$ & HWL6 \\
\hline S1 & 8.45 & 4.35 & 8.45 & 4.69 & 9.00 & 4.75 & 9.15 & 4.95 & 9.30 & 5.04 & 9.30 & 5.04 \\
\hline $\mathrm{S} 2$ & 9.00 & 3.61 & 8.45 & 4.30 & 9.00 & 4.17 & 9.30 & 4.59 & 9.45 & 4.71 & 10.15 & 4.75 \\
\hline $\mathrm{S} 30$ & 8.45 & 3.88 & 9.00 & 5.02 & 9.30 & 5.14 & 9.45 & 5.18 & 10.00 & 5.28 & 10.15 & 5.32 \\
\hline S5 & 9.00 & 4.93 & 9.30 & 5.27 & 9.45 & 5.35 & 10.00 & 5.50 & 10.45 & 5.64 & 11.00 & 5.67 \\
\hline S6 & 9.00 & 5.01 & 9.00 & 5.34 & 9.30 & 5.42 & 9.45 & 5.56 & 10.00 & 5.70 & 10.15 & 5.70 \\
\hline S7 & 8.45 & 4.80 & 9.00 & 5.13 & 9.15 & 5.23 & 9.30 & 5.42 & 9.45 & 5.64 & 10.15 & 5.69 \\
\hline S9 & 8.45 & 5.23 & 9.15 & 5.54 & 9.45 & 5.47 & 9.45 & 5.79 & 10.15 & 5.95 & 10.30 & 5.93 \\
\hline ST13 & 9.15 & 5.12 & 9.30 & 5.44 & 10.00 & 5.70 & 10.00 & 5.96 & 10.45 & 6.10 & 10.45 & 6.08 \\
\hline T11 & 8.45 & 4.72 & 8.45 & 5.10 & 9.45 & 5.16 & 9.30 & 5.30 & 9.45 & 5.42 & 9.45 & 5.44 \\
\hline T10 & 9.00 & 5.94 & 9.15 & 5.64 & 9.30 & 5.76 & 9.45 & 5.90 & 10.15 & 6.05 & 10.15 & 6.04 \\
\hline M3 & & & 9.30 & 4.40 & 9.00 & 4.99 & 9.00 & 4.94 & 9.30 & 5.04 & 10.00 & 5.00 \\
\hline M8 & 9.15 & 5.40 & 9.30 & 5.93 & 9.15 & 5.58 & 9.30 & 5.68 & 9.45 & 5.86 & 10.30 & 5.88 \\
\hline M4 & 8.45 & 4.31 & 10.00 & 5.10 & 9.45 & 4.63 & 9.45 & 5.08 & 10.15 & 4.64 & & \\
\hline M15 & 9.00 & 5.30 & 8.45 & 5.59 & 9.30 & 5.81 & 9.30 & 5.81 & 10.00 & 5.99 & 10.30 & 5.99 \\
\hline M14 & 8.45 & 5.16 & 8.45 & 5.56 & 9.30 & 5.94 & 9.30 & 5.94 & 10.00 & 6.14 & 10.30 & 6.07 \\
\hline M22 & 9.45 & 6.60 & 9.15 & 6.14 & 10.15 & 6.45 & 10.15 & 6.45 & 10.30 & 6.55 & 10.45 & 6.58 \\
\hline M26 & 9.15 & 6.75 & 9.00 & 6.84 & 9.45 & 6.84 & 10.00 & 6.78 & 10.30 & 7.08 & 10.30 & 7.04 \\
\hline B16 & 9.15 & 4.23 & 9.15 & 6.01 & 9.30 & 6.12 & 9.45 & 6.23 & 10.00 & 6.31 & 11.15 & 5.82 \\
\hline B19 & 9.15 & 5.48 & 9.30 & 5.76 & 9.45 & 6.76 & 9.45 & 6.28 & 10.15 & 6.46 & 10.45 & 6.44 \\
\hline B20 & 9.45 & 5.56 & 9.30 & 5.82 & 9.45 & 6.02 & 9.45 & 6.12 & 10.30 & 6.26 & 10.45 & 6.28 \\
\hline B23 & 9.15 & 5.42 & 9.15 & 5.86 & 9.45 & 6.10 & 9.45 & 6.16 & 10.45 & 6.86 & 10.45 & 6.36 \\
\hline G12 & & & & & 10.00 & 5.91 & 9.45 & 6.11 & 10.00 & 6.21 & 11.15 & 6.25 \\
\hline G18 & 9.30 & 4.71 & 9.45 & 4.94 & 10.15 & 5.13 & 10.30 & 5.27 & 11.00 & 5.47 & 11.30 & 5.45 \\
\hline H17 & 9.15 & 5.16 & 9.45 & 5.32 & 10.30 & 5.48 & 10.00 & 5.62 & 11.00 & 5.72 & 11.00 & 5.66 \\
\hline GH21 & 9.45 & 5.45 & 10.15 & 5.67 & 11.00 & 5.90 & 10.45 & 5.86 & 11.45 & 5.90 & 11.45 & 5.94 \\
\hline R24 & 10.00 & 4.50 & 10.00 & 4.86 & 10.45 & 5.14 & 11.15 & 5.26 & 12.00 & 5.38 & 11.45 & 5.30 \\
\hline $\mathrm{R} 25$ & 10.00 & 5.08 & 10.15 & 5.26 & 11.00 & 5.42 & 11.15 & 5.53 & 11.45 & 5.64 & $\begin{array}{l}00 \mathrm{AM}, \\
21 \mathrm{March}\end{array}$ & 5.62 \\
\hline $\mathrm{R} 27$ & 10.00 & 5.38 & 10.00 & 5.58 & 10.45 & 5.78 & 10.45 & 5.84 & 11.15 & 6.00 & 11.30 & 5.90 \\
\hline $\mathrm{R} 28$ & 10.30 & 3.82 & & & & & & & & & & \\
\hline R29 & 10.30 & 4.75 & 10.15 & 5.05 & 10.45 & 5.17 & 11.15 & 5.33 & 11.45 & 5.37 & 11.45 & 5.29 \\
\hline
\end{tabular}

levels (HW level minus succeeding LW level) for any tidal cycle and are equal to twice the tidalwave amplitude at that point. For stations where gaps in the data coincided with the occurrences of $\mathrm{HW} / \mathrm{LW}$, tidal ranges were computed using the corresponding predicted values from the harmonic analyses of the water-level time series (section 4), provided the phases were found to match. The mean ranges are listed in table 2. The general features were as follows.

As expected for the Equinoctial Spring Phase, HW levels increased over successive tidal cycles (figure 5) at individual stations. The tidal range was significantly lower during the first tidal cycle at several locations. This difference between the first two cycles was higher on the Matla and Bidya. The largest change in range from the first cycle to the second occurred at B16 (Jharkhali Bali; figure 4).
The range increased from mouth to head in all estuaries. On the Saptamukhi, Matla, and the surveyed part of the Harinbhanga, the range increased till the last station. On the Thakuran, Bidya, and Raimangal, the range decreased at the last station, and this decrease was also seen over the last two stations on the Gomdi, which was the narrowest and shortest of the channels surveyed.

The difference in range across the tidal cycles decreased towards the head of the estuary; the minimum difference was observed at Canning, where the range varied by just $0.06-0.12 \mathrm{~m}$ over the six cycles. For most of the stations, the maximum (minimum) HW (LW) levels occurred during HW5 (LW4) on the morning of 20 March, following the Full Moon at $11 \mathrm{pm}$ on 19 March. Deviations from this pattern also existed, however, at several stations. 
Table 6. Times (IST) of reaching Low Water (LW) and corresponding LW levels (m). Grey cells indicate missed observations. All times are in IST.

\begin{tabular}{|c|c|c|c|c|c|c|c|c|c|c|}
\hline \multirow{2}{*}{$\begin{array}{l}\text { Station } \\
\text { number }\end{array}$} & \multicolumn{2}{|c|}{ LW1: 18 March } & \multicolumn{2}{|c|}{ LW2: 19 March } & \multicolumn{2}{|c|}{ LW3: 19 March } & \multicolumn{2}{|c|}{ LW4: 20 March } & \multicolumn{2}{|c|}{ LW5: 20 March } \\
\hline & $\mathrm{PM}$ & LWL1 & $\mathrm{AM}$ & LWL2 & $\mathrm{PM}$ & LWL3 & $\mathrm{AM}$ & LWL4 & $\mathrm{PM}$ & LWL5 \\
\hline S1 & 2.45 & 0.38 & 3.15 & 0.02 & 3.30 & 0.14 & 4.00 & 0 & 4.15 & 0.16 \\
\hline $\mathrm{S} 2$ & 2.30 & 0.09 & 3.45 & 0.04 & 3.30 & 0.03 & 3.45 & 0.03 & 4.30 & 0.03 \\
\hline $\mathrm{S} 30$ & 2.00 & 0.00 & 4.00 & 0.00 & 4.00 & 0.00 & 4.15 & 0.00 & 4.30 & 0.00 \\
\hline S5 & 3.45 & 0.53 & 4.15 & 0.26 & 4.30 & 0.16 & 5.30 & 0.00 & 5.15 & 0.27 \\
\hline S6 & 3.15 & 0.60 & 4.00 & 0.21 & 4.00 & 0.20 & 4.30 & 0.00 & 4.45 & 0.25 \\
\hline $\mathrm{S} 7$ & 3.15 & 0.48 & 3.45 & 0.14 & 4.00 & 0.09 & 4.30 & 0.00 & 4.45 & 0.18 \\
\hline S9 & 3.45 & 0.60 & 4.15 & 0.20 & 4.30 & 0.19 & 5.00 & 0.00 & 5.15 & 0.32 \\
\hline $\mathrm{ST} 13$ & 4.00 & 0.12 & 4.30 & 0.00 & 4.45 & 0.23 & 5.15 & 0.00 & 6.00 & 0.06 \\
\hline $\mathrm{T} 11$ & 3.15 & 0.36 & 4.15 & 0.84 & 4.15 & 0.12 & 4.45 & 0.20 & 4.45 & 0.04 \\
\hline T10 & 3.30 & 0.62 & 4.15 & 0.00 & 4.45 & 0.3 & 5.30 & 0.00 & 5.15 & 0.3 \\
\hline M3 & & & 4.00 & 0.05 & 4.30 & 0.10 & 4.30 & 0.02 & 5.00 & 0.04 \\
\hline M8 & 3.15 & 0.82 & 4.30 & 0 & 4.00 & 0.42 & 4.30 & 0.08 & 4.45 & 0.33 \\
\hline M4 & 3.00 & 0.00 & 3.30 & 0.04 & 4.45 & 0.26 & 4.30 & 0.00 & & \\
\hline M15 & 3.45 & 0.61 & 4.30 & 0.09 & 4.30 & 0.21 & 5.00 & 0.00 & 5.15 & 0.10 \\
\hline M14 & 3.45 & 0.36 & 4.30 & 0.24 & 4.15 & 0.24 & 5.15 & 0.00 & 5.15 & 0.22 \\
\hline M22 & 4.30 & 0.39 & 5.15 & 0.12 & 5.15 & 0.11 & 6.00 & 0.11 & 6.00 & 0.00 \\
\hline M26 & 4.15 & 0.07 & 4.30 & 0.25 & 5.00 & 0.13 & 6.15 & 0.00 & 6.00 & 0.24 \\
\hline B16 & 4.15 & 0.30 & 4.30 & 0.00 & 4.45 & 0.03 & 5.15 & 0.01 & 5.45 & 0.00 \\
\hline B19 & 4.30 & 0.40 & 5.00 & 0.00 & 5.15 & 0.21 & 5.30 & 0.00 & 6.00 & 0.07 \\
\hline B20 & 4.45 & 0.44 & 5.30 & 0.00 & 5.45 & 0.22 & 5.00 & 0.20 & 5.15 & 0.12 \\
\hline B23 & 4.45 & 0.42 & 5.15 & 0.20 & 5.00 & 0.16 & 6.00 & 0.00 & 6.00 & 0.12 \\
\hline G12 & & & & & 4.45 & 0.22 & 5.15 & 0.00 & 5.30 & 0.06 \\
\hline G18 & 3.45 & 0.01 & 4.45 & 0.02 & 4.45 & 0.11 & 5.30 & 0.00 & 4.30 & 0.00 \\
\hline H17 & 4.00 & 0.58 & 4.45 & 0.18 & 4.45 & 0.26 & 5.15 & 0.04 & 5.45 & 0.16 \\
\hline GH21 & 4.15 & 0.50 & 4.00 & 0 & 5.15 & 0.25 & 5.30 & 0.10 & 6.00 & 0.26 \\
\hline $\mathrm{R} 24$ & 4.30 & 0.00 & 5.00 & 0.02 & 5.00 & 0.11 & 6.00 & 0.00 & 5.45 & 0.14 \\
\hline R25 & 4.15 & 0.66 & 5.00 & 0.28 & 5.00 & 0.34 & 5.45 & 0.11 & 5.45 & 0.27 \\
\hline $\mathrm{R} 27$ & 5.15 & 0.60 & 6.00 & 0.21 & 6.15 & 0.19 & 6.15 & 0.00 & 7.15 & 0.04 \\
\hline $\mathrm{R} 28$ & & & & & 5.45 & 0.18 & 6.00 & 0.00 & 5.45 & 0.00 \\
\hline R29 & 5.15 & 0.08 & 5.30 & 0.01 & 6.15 & 0.09 & 6.30 & 0.00 & 6.45 & 0.10 \\
\hline
\end{tabular}

Figure 6 also displays the line of best fit for the variations of the mean tidal ranges with distance for all the estuaries. Departures of the actual tidal ranges at each station from the line of best fit are obvious, as also are their changes over the various tidal cycles. The $\mathrm{R}^{2}$ values (figure 6 ) indicate the fraction of the variance that can be explained by the linear fit. This fraction varied from a minimum (0.47) on the Gomdi to a maximum (0.920.96) on the Matla, Bidya, and the Harinbhanga. The mean rate of increase of the tidal range was of the order of $2.2-2.4 \mathrm{~cm} / \mathrm{km}$ in the Saptamukhi, Thakuran, and Matla, and it decreased eastward: the mean rate of increase was $1.7 \mathrm{~cm} / \mathrm{km}$ in the Bidya, $1.1 \mathrm{~cm} / \mathrm{km}$ in the Gomdi and Harinbhanga, and $0.7 \mathrm{~cm} / \mathrm{km}$ in the Raimangal. Thus, in general, the tidal range increased as the tide propagated in each of the estuaries in all the tidal cycles, but the degree and rates of amplification over the various estuarine stretches were not uniform. In the following paragraphs, we describe for each estuary the variations of the observed water levels (figure 5 ) and tidal ranges (figure 6).

The SEG, the stronger branch of the Saptamukhi, flows straight and wide in its last $10 \mathrm{~km}$ to the Bay of Bengal. North of this stretch, both the SEG and the SWG, the western branch of the river, begin to meander and converge and practically lose themselves in the network of channels (figure 3). The Jagaddal, flowing parallel to the SEG and also debouching into the bay, is an important easterly branch of the SEG, having links with the adjoining estuary, the Thakuran, through the Dhanchi Khaal, Pakhi Nala, and Shibua Gaang. It is on the Jagaddal that Indrapur, the station (S1) about $8 \mathrm{~km}$ north of the mouth and closest to the 

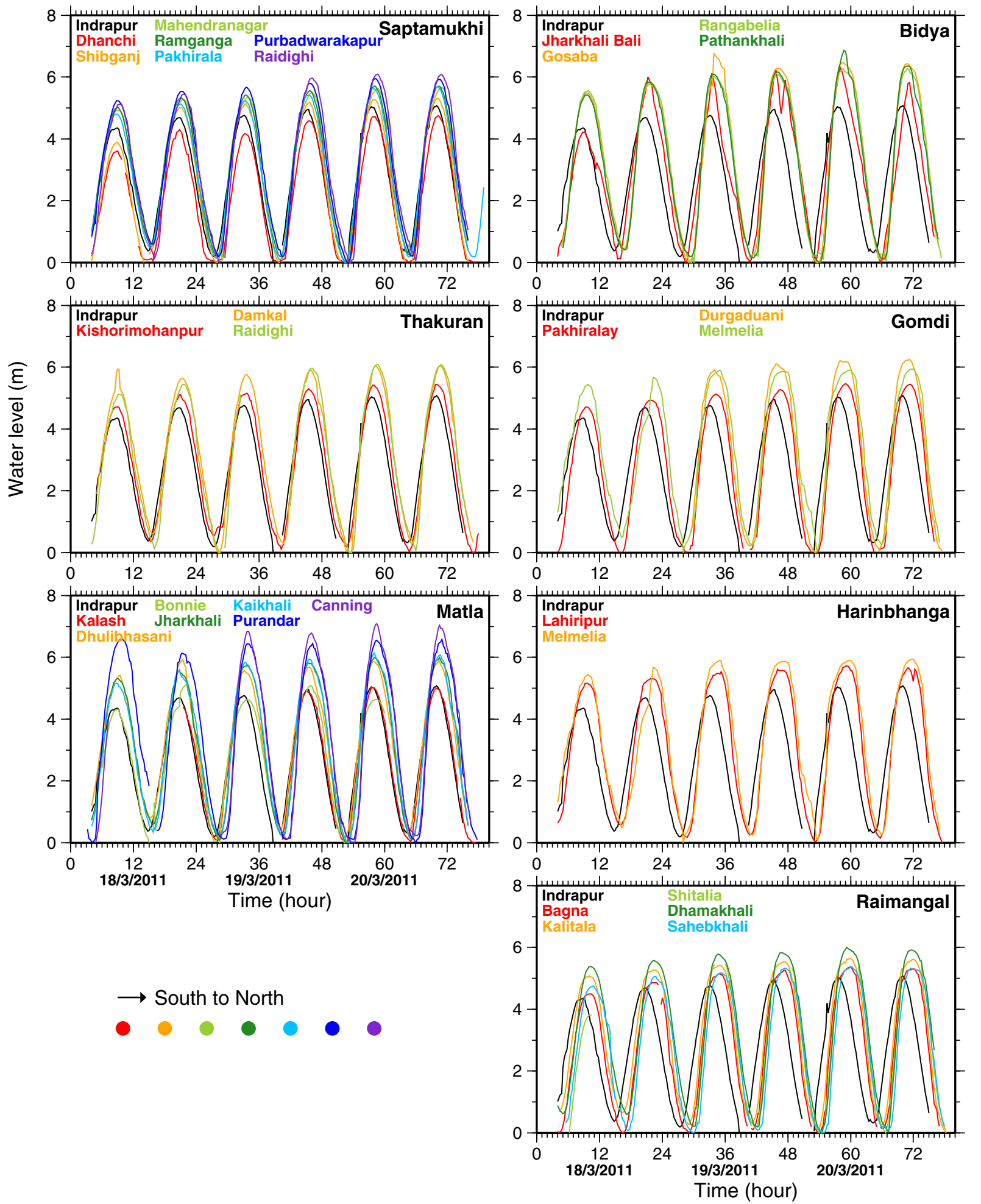

Figure 5. Observed water level variations in the seven estuaries of the SES. The three western estuaries are shown in the panels on the left and the four eastern estuaries in the panels on the right. Symbols on the lower left indicate the use of colours for the curves in order from mouth to head. The water level at Indrapur (S1), on the Saptamukhi, is shown in the panels for all the estuaries; the water level at Indrapur is considered representative of the water level at the mouth of all estuaries.

Bay of Bengal, was located; we use the Indrapur data to represent the conditions at the mouth of all seven estuaries (figures 5 and 6). Mean tidal ranges in the Saptamukhi varied between 4.32 and $5.58 \mathrm{~m}$ (table 2 and figure 6) over the 72-hour observation period. The observed tidal range variations during 

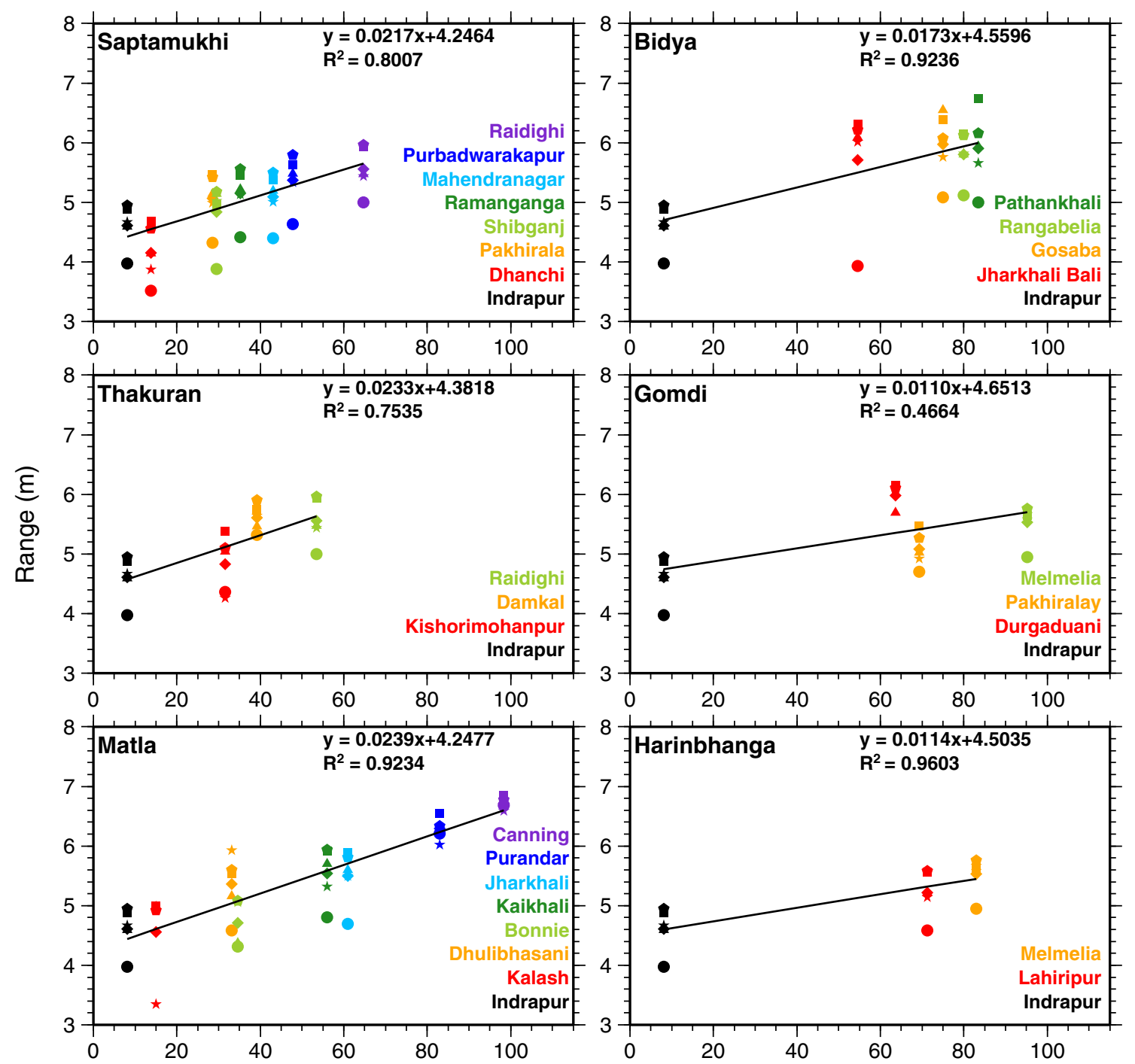

Distance $(\mathrm{km})$ north of seaface
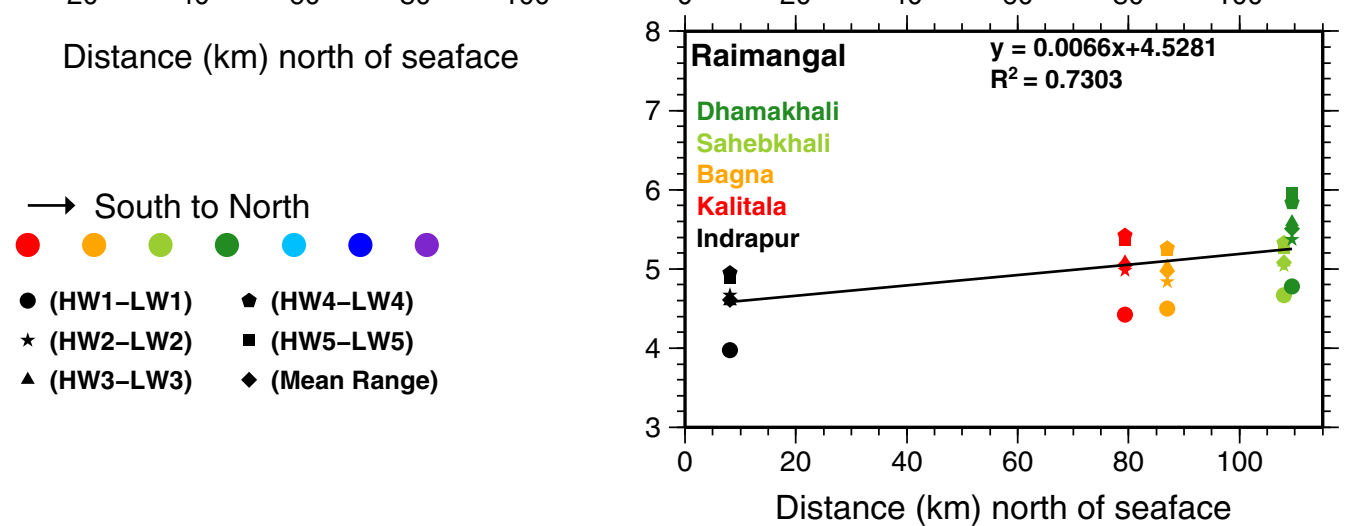

Figure 6. Observed amplification of the tide in the seven estuaries of the SES. As in figure 5, the data for Indrapur are plotted in all panels. The abscissa shows the distance $(\mathrm{km})$ measured along the channels from the seaface, which is considered to be at $21.6025^{\circ} \mathrm{N}$ for all seven estuaries.

this period were found to lie between the minimum (maximum) value of $3.52(5.96) \mathrm{m}$, observed at S2 (ST13), during the first (fifth) tidal cycle. The tidal range increased from mouth to head, but it decreased between Indrapur and Dhanchi (S2), a station located at the junction of the Jagaddal and Dhanchi Khaal.

T11 (Kishorimohanpur) is the southernmost of the group of three stations on the Thakuran and lies directly in the path of the tidal wave as 
it propagates north along this estuary. T10 (Damkal) lies to its northwest, at the confluence of the Kuemari Khaal, river Raidighi, and the Thakuran (figure 3). The Thakuran converges rapidly in width between $\mathrm{T} 10$ and T11, and meanders sharply to the west and then to the east on this stretch. As can be seen from figure 5, the lowest HW levels $(4.72-5.44 \mathrm{~m})$ for all tidal cycles are observed at T11. Highest HW levels occurred at either T10 or ST13, following a pattern similar to that observed on the Saptamukhi. During HW1-HW3 (morning of 18 March to morning of 19 March), HW levels were highest at T10 followed by those at ST13. From HW4-HW6, HW levels were highest at ST13, followed by those at T10. On the Thakuran, the mean tidal range varied from $4.93 \mathrm{~m}$ at T11 to a maximum of $5.61 \mathrm{~m}$ at T10 (table 2 and figure 6).

River Matla divides into two branches south of the Herobhanga Reserve Forest (figures 3 and 4). The short western branch flows south as the river Ajmalmari-Kankalmari-Suia Gaang and re-unites with the eastern branch or the Matla proper. The stronger eastern branch merges with the Bidya (a tributary of the Raimangal), and their united stream flows southward into the Bay of Bengal as the straight and wide river Matla (or the Matla-Bidya). The west-east-flowing Suia Gaang links the Thakuran and the Matla. Water-level observations at M26 (Canning) were missed during the first two tidal cycles, but the HW level and range were maximum here from the third tidal cycle onwards (figure 5). Though the tide amplified throughout the Matla, the range was lower at M4 (Bonnie Camp), which lies not on the Matla proper, but on a smaller channel (the Sundar Kati Khaal) connecting the Suia Gaang and river Ajmalmari-Kankalmari (figure 3). Likewise, there was a decrease in the range between Indrapur and M3 (Kalash), the station closest to the mouth of the Matla: Kalash, like Bonnie Camp, is not located on the Matla proper, but on the nearly $20 \mathrm{~m}$ deep northwesterly stretch of the Dhulibhasani Gaang (figure 3) flowing into the Matla.

River Bidya (figure 4), flowing southwest past B20 (Rangabelia) and the Kartal Gaang (the last stretch of the Hogol linking the Matla and Bidya), flowing southeast past B23 (Pathankhali), converge at B19 (Gosaba). Still following a highly meandering course, the Bidya widens considerably as it flows southwest and then southeast, meeting the Gomdi Khaal, almost opposite to B16 (Jharkhali Bali). The Bidya finally falls into the eastern branch of the Matla, about $35 \mathrm{~km}$ due north of the seaface. From the point of confluence with the Gomdi, the Bidya and the Bidya-Matla lie completely exposed to the Bay of Bengal. The highest HW levels and the maximum tidal range occurred at all stations in this group over various tidal cycles in a rather scattered manner: at B20 during HW1, at B16 during HW2, at B19 during HW3, HW4 and HW6, and at B23 during HW5. This scatter is unlike the more organized patterns of observed headward increase of HW levels for the three western estuaries. The maximum decay of the tidal amplitude, $37 \mathrm{~cm}$, was observed in the short, $5 \mathrm{~km}$ stretch between B19 and B20 during the third tidal cycle. Significant decay of the tidal amplitude (by $30 \mathrm{~cm}$ ) also occurred in the stretch on the Kartal Gaang between B19 and B23 during the third tidal cycle. A striking feature of the Bidya is the peakedness of the tide curve at B16 (Jharkhali Bali) and the distinct tendency for double peaks at both HW and LW for all stations.

The Gomdi (Gomor) follows a southwesterly course and is connected with the Raimangal (figure 4). The Durgaduani Khaal, oriented roughly north-south, connects the Bidya and the Gomdi. Station G12 (Durgaduani) is situated on it at its southern end. Both the Bidya and the Gomdi Khaal follow almost parallel northeasterlysouthwesterly courses before falling into the Matla as described above. GH21 (Melmelia) lies at the confluence of the Gomdi (known as the Melmel Khaal on this stretch) and the Ganral GaangDatta'r Gaang (figure 4), which flows south from this point to join the Harinbhanga. Of all the stations on the Gomdi, G18 (Pakhiralay) (figure 5), had the lowest HW levels throughout the 72-hour period of observation. Maximum HW levels occurred once each at GH21 and G12 during HW1 and HW6, respectively. On the Gomdi Khaal, the major tidal amplification occurred only between stations G18 and GH21: 37, 31, and $24 \mathrm{~cm}$, respectively, during the second, third, and fourth tidal cycles. Decay of the tidal wave was observed between G12 and G18 (by 33, 42, and $34 \mathrm{~cm}$ ) during the third, fourth, and fifth tidal cycles, respectively. Data for the first two cycles are missing at G12.

The two observation stations situated on the Harinbhanga, H17 (Lahiripur) and GH21 (Melmelia), are situated 71 and $83 \mathrm{~km}$ inland from the seaface. This estuary is oriented south-north, and, once again, the familiar pattern of HW levels increasing headward from H17 to GH21 was observed. Double peaks exist on the curves for both stations.

On the Raimangal, the HW levels were found to increase throughout the six successive tidal cycles from R24 (Bagna) to R27 (Dhamakhali), which is situated $110 \mathrm{~km}$ north of the seaface and is the northernmost station on this estuary and in the SEP area. Most of the HW/LW levels at R28 (Shitalia) could not be measured. The first distinct signs of decrease in the HW levels could be detected 
at R29 (Sahebkhali), situated $108 \mathrm{~km}$ north of the seaface. Over all tidal cycles, tidal amplitudes were observed to decrease at R29 (Sahebkhali).

The tendency of formation of double peaks, at both HW and LW, in the tide curves for several stations mentioned above is due to the relatively longer $\mathrm{HW} / \mathrm{LW}$ stands of the tide observed at these stations which also accounts for the significant duration asymmetry observed in the tides in the SES. We examine this tidal stand in section 5 .

\section{The tidal constituents}

The 72-hour observation period provides a dataset that is not long enough to separate the major tidal constituents. In particular, it is not possible to distinguish among the major semi-diurnal $\left(M_{2}\right.$, $S_{2}$, and $N_{2}$ ) or diurnal $\left(K_{1}\right.$ and $\left.O_{1}\right)$ bands; the minimum duration required to separate these constituents being 355 hours (Foreman 2004, p. 14). However, the 72-hour duration was chosen, because it is the minimum record length for which the semidiurnal tide can be distinguished from the diurnal tide (Shetye et al. 1995; Foreman 2004). Therefore, following Shetye et al. (1995), who analyzed a similar 72-hour record of observed water levels in the Mandovi-Zuari estuaries, we determined the amplitudes and phases of eight constituent bands (table 7 ) by subjecting the data to a harmonic analysis using a least-squares approach. The Tidal Analysis Software Kit (TASK 2000) software (Bell et al. 1998) was used to determine these eight constituent bands. In the analysis, all the semi-diurnal constituents were lumped into the $M_{2}$ frequency, all the diurnal constituents into the $K_{1}$ frequency, and so on. Missing data do not preclude the leastsquares fit performed by TASK 2000 , but the data gaps were too many in the case of R28 (Shitalia);

Table 7. The eight constituent bands used for harmonic analysis and least-square fitting of the observed data (after Shetye et al. 1995).

\begin{tabular}{lcl}
\hline $\begin{array}{l}\text { Name of } \\
\text { the band }\end{array}$ & $\begin{array}{c}\text { Range of frequencies } \\
\text { in the band } \\
\text { (cycles/hour) }\end{array}$ & $\begin{array}{c}\text { Frequencies used } \\
\text { for analyses } \\
\text { (cycles/hour) }\end{array}$ \\
\hline Diurnal & $0.0279-0.0557$ & $0.0418\left(K_{1}\right)$ \\
Semi-diurnal & $0.0666-0.0944$ & $0.0805\left(M_{2}\right)$ \\
8-hourly & $0.1069-0.1347$ & $0.1208\left(M_{3}\right)$ \\
6-hourly & $0.1471-0.1749$ & $0.1610\left(M_{4}\right)$ \\
5-hourly & $0.1883-0.2167$ & $0.2028\left(2 K_{5}\right)$ \\
4-hourly & $0.2276-0.2554$ & $0.2415\left(M_{6}\right)$ \\
3.5-hourly & $0.2694-0.2974$ & $0.2833\left(3 K_{7}\right)$ \\
3-hourly & $0.3081-0.3359$ & $0.3220\left(M_{8}\right)$ \\
\hline
\end{tabular}

therefore, the amplitudes and phases reported here (figure 7), exclude this station. The analysis shows that except at Canning (M26), where it has an amplitude of $15 \mathrm{~cm}$, the 5-hourly $2 M K_{5}$ band and the 3.5 -hourly $3 M K_{7}$ band (not shown in the figure) have amplitudes lower than $10 \mathrm{~cm}$ at all stations; at most stations, the amplitude of these two bands is less than $5 \mathrm{~cm}$.

The amplitude of the $M_{2}$ or semi-diurnal, band was an order of magnitude higher than that of the other constituents (figure 7). As expected, owing to the amplification of the tide as it propagates into the estuary, the amplitude increased headward in the major channels, with the strongest amplification (figure 7) occurring in the Matla (towards Purandar and Canning; figure 4) and in the Bidya (towards both Pathankhali and Rangabelia; figure 4). The semi-diurnal amplitude was weaker in the eastern estuaries, the Harinbhanga and the Raimangal. The phase of this band increased gradually away from the mouth and it showed much less scatter with distance than did the phase of the other constituents (figure 7).

Unlike the semi-diurnal amplitude, neither was the diurnal $\left(K_{1}\right)$ amplitude a function of the distance from the mouth, nor did the diurnal phase show the gradual increase with distance (figure 7 ). The diurnal band dominated next to the semidiurnal (figure 7) in the Saptamukhi stations (S1, S2, S6, S7 and S30) and in the wide stretches of the Thakuran (T11) and Matla (M8). It was the second and third dominant bands (after the semi-diurnal band) in the majority of the stations, and had its maximum amplitude at S30. At Kalash (M3), the amplitudes of the $K_{1}$ and the 8-hourly $M_{3}$ bands were comparable. Likewise, at M22 and R25, the $K_{1}$ and $M_{6}$ band amplitudes were nearly equal. Since the diurnal amplitude does not increase headward, unlike the amplitudes at higher frequencies, other bands notably the $M_{3}, M_{4}$ and $M_{6}$ tend to become more important away from the mouth.

The 8-hourly $\left(M_{3}\right)$ band had significant amplitudes exceeding $10 \mathrm{~cm}$ only at 5 stations (figure 7). Its maximum amplitude occurred at M26 (Canning), at the head of the Matla. At this station and at stations B19 and B23 on the Bidya, $M_{3}$ appeared as the fourth dominant band after $M_{2}$. At M4 (Bonnie Camp), the diurnal, 8-hourly, and 6-hourly bands had comparable amplitudes. Station M4 was also one of the three outliers in the phase-distance plot for this band (figure 7). The phase gradually increased away from the mouth, but the phases at M4, B16, and GH21 were strikingly different.

The 6-hourly $\left(M_{4}\right)$ band dominated (following the semi-diurnal) at 17 stations. Its amplitude also increased gradually headward (figure 7), making it more significant in the surveyed part of the eastern estuaries, the Gomdi and Harinbhanga (GH21) 


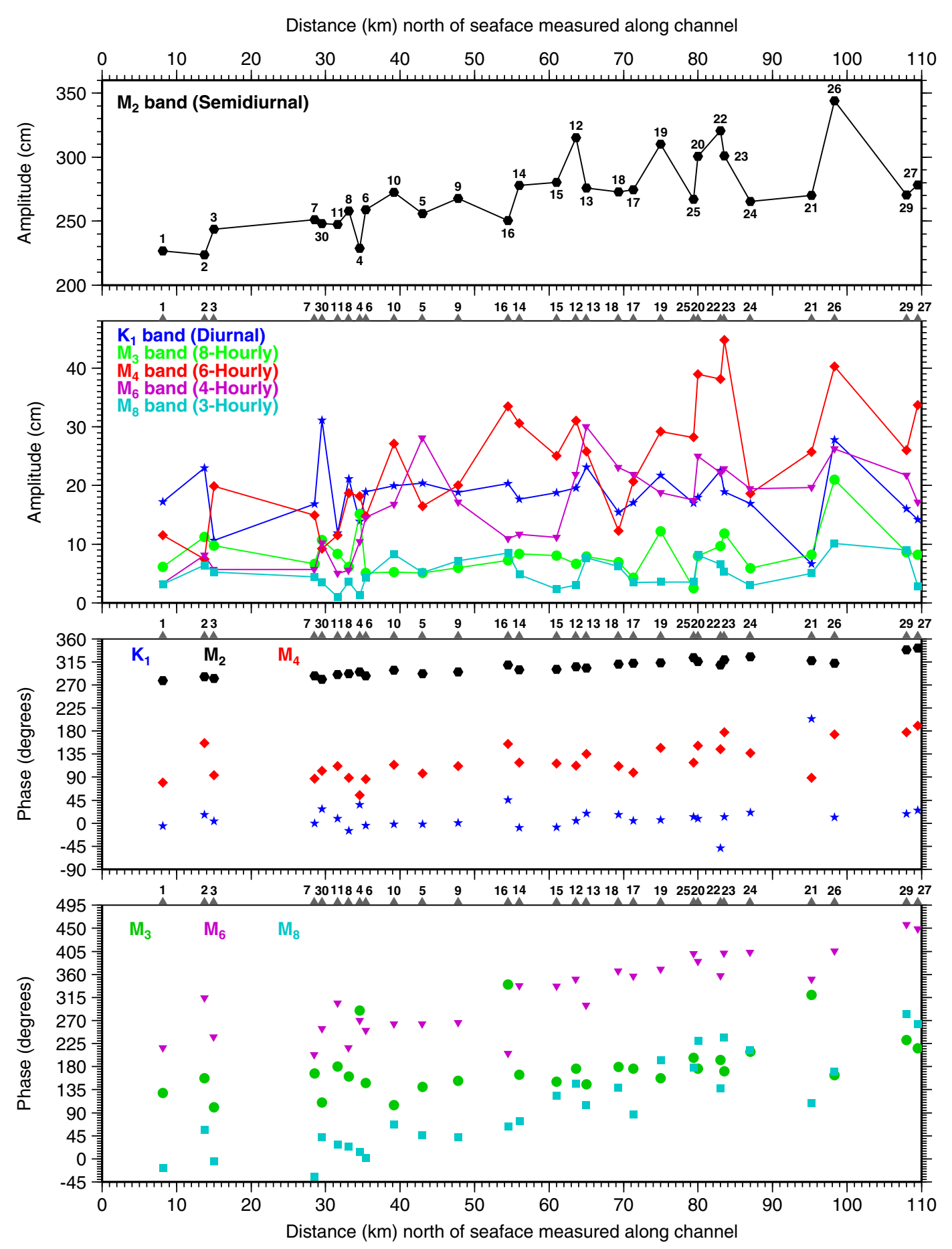

Figure 7. Amplitudes (m) and phases (degrees) of the tidal constituent bands. Note the different ordinate scale for the $M_{2}$ amplitude.

and the Raimangal (R24, R27, R29), in the upper reaches of the Saptamukhi and Thakuran (S9 and T10) and at all stations on the Matla (M3, M4, M14, M15, M22, and M26) and the Bidya (B16, B19, B20, and B23). This band occurred at another eight stations as the second-most dominant (compared to the $M_{2}$ band). The $M_{4}$ phase also increased gradually away from the mouth, the outliers being S2, M4, B16, B23 and GH21 (figure 7 ). In the SES, this 6-hourly band is important in or near the mouths of the west-east-oriented channels that link the major south-north-oriented estuaries. Locally, their presence is known to cause four HW and LW levels in a day and these channels are therefore called duania/doania, which means 'channel joining two rivers'. 
Table 8. Characteristics of the amplitudes of the constituent bands emerging from the harmonic analysis (SD: Standard deviation).

\begin{tabular}{lclcrrr}
\hline $\begin{array}{l}\text { Constituent } \\
\text { band }\end{array}$ & $\begin{array}{c}\text { Maximum } \\
(\mathrm{cm})\end{array}$ & \multicolumn{1}{c}{ At station } & $\begin{array}{c}\text { Minimum } \\
(\mathrm{cm})\end{array}$ & At station & $\begin{array}{c}\text { Mean } \\
(\mathrm{cm})\end{array}$ & $\begin{array}{r}\text { SD } \\
(\mathrm{cm})\end{array}$ \\
\hline$K_{1}$ & 30 & S30 (Shibganj) & 7 & GH21 (Melmelia) & 18 & 5 \\
$M_{2}$ & 344 & M26 (Canning) & 224 & S2 (Dhanchi) & 271 & 28 \\
$M_{3}$ & 21 & M26 (Canning) & 2 & R25 (Kalitala) & 8 & 4 \\
$M_{4}$ & 45 & B23 (Pathankhali) & 7 & S2 (Dhanchi) & 24 & 10 \\
$2 K_{5}$ & 15 & M26 (Canning) & 0 & T10 (Damkal) & 5 & 3 \\
$M_{6}$ & 30 & ST13 (Raidighi) & 3 & S1 (Indrapur) & 16 & 8 \\
$3 K_{7}$ & 8 & M4 (Bonnie Camp) & 0 & M8 (Dhulibhasani) & 3 & 2 \\
\hline
\end{tabular}

However, the data suggest that the amplitude of the 4-hourly $\left(M_{6}\right)$ band is comparable to that of the 6-hourly band at several stations away from the mouth (figure 7). This band dominated at five stations: S5, ST13, H17, G18 and R24. The phase increased headward, but there were a few outliers (figure 7).

The 3-hourly $\left(M_{8}\right)$ band was not dominant at any station and was absent (amplitude less than 5-10 cm) at most of them and, as expected for such a weak mode, the phase showed considerable scatter (figure 7).

Thus, other than the semi-diurnal component, the tide in the SES consists mostly of three other constituent bands, which are any three of the $K_{1}$, $M_{3}, M_{4}$, and $M_{6}$ bands. The $M_{4}$ and $M_{6}$ bands are the most frequently occurring bands immediately following the semi-diurnal one, particularly in the landward stations situated at channel confluences. This suggests the strong interactions between the incoming tide and the channel geometry. M26 (Canning) is the only station where the tide is composed of all the eight constituent bands, seven of them having significant amplitudes of $10 \mathrm{~cm}$ or more. At this location, even the $3 M K_{7}$ band amplitude $(6 \mathrm{~cm})$ is greater than $5 \mathrm{~cm}$.

A summary of these eight constituent bands is given in table 8 .

\section{The stand of the tide}

Since the tidal water level curve is sinusoidal, the rate of change of water level (WL) is low around high and low tide. At some places, however, the water level has been noted to remain practically stationary during HW or LW, the change in the level being so slow as to be imperceptible. Such a state has been called the 'Stand of the Tide' or 'Platform Tide' (NTC 2010; NOAA 2000). This phenomenon has been ascribed to purely tidal causes and is not connected to slack water or tidal currents. A tidal stand is known to prevail in some parts of the world that have complex tidal regimes consisting of double HW/LWs or $\mathrm{HW} / \mathrm{LW}$ stands. Well-known examples are ports in the English Channel such as Poole Harbour (small tidal range, double HW; Heritage 2006), Weymouth (small tidal range, double LW; Heritage 2006), Portland (LW stand; Heritage 2006), and Southampton (HW or 'Young Flood' Stand; Pugh 1987). Other examples include the coast of the Netherlands between Scheveningen and Haringvlietsluizen (UKHO 2011), the mouth of the river Rhine, the ports of Hoek van Holland and Rotterdam (double LW; Pugh 1987; UKHO 2011) and Invergordon on the Scottish coast (UKHO 2012). In all these places, the development of the double $\mathrm{HW} / \mathrm{LWs}$, and possibly the tidal stand, has been attributed to the generation of primarily the quarter-diurnal and the 6th diurnal harmonics due to the distortion of the $M_{2}$ constituent as it propagates upstream along the estuarine channel with continuously decreasing depths (Pugh 1987). The duration of the tidal stand is dependent on the tidal range, with locations having small tidal ranges expected to have longer stands. Nevertheless, at locations having a high tidal range and a tendency for double tides (two nearly equal HWs or LWs separated by a small minimum or maximum value), long durations of the tidal stand can occur (NTC 2010; NOAA 2000). The phenomenon is also observed to be more prominent during the Spring phases of the tide (Pugh 1987; Heritage 2006; UKHO 2011, 2012).

Though the tidal range in the SES is high, slow changes in the water levels were evident in the water-level data for several stations, suggesting the existence of a stand. This stationarity in tidal elevations was noted and recorded by the observers at most of the stations where it occurred. They described the conditions as 'a stillness of the water, similar to the calm frequently observed just before the outbreak of a storm'.

Such an imperceptible change in the WL was evident at, for example, R24 (Bagna) during HW5 
(figure 8a). The WL changed very slowly around the HW5 mark and the level appeared to stand still for over an hour. It is such stationarity or quasistationarity of the WL that is referred to as a tidal stand. In contrast, the change in the WL at B16 (Jharkhali Bali) was even more rapid than for a pure $M_{2}$ tide, and therefore we do not see a stand at B16. Note that the pure $M_{2}$ tide cannot, by definition, exhibit a stand. Similar slow changes around the HW mark were seen at several stations. Likewise, the WL can change slowly around the LW mark as well, as was seen at S2 (Dhanchi) during LW3 (figure 8d). At S6 (Ramganga), however, the change was comparable to that seen for the pure $M_{2}$ tide, implying that a LW stand exists at S2, but not at S6, during LW3. If the rate of rise (figure 8b) or fall (figure 8e) of the WL is plotted instead, it is seen to hover around zero for some time around the HW or LW mark if a stand exists at the station. For the constant sampling interval used here, the rates of rise and fall are proportional to the WL differences between consecutive observations.

At times, at some stations, the difference in the WL between two successive measurements was identically zero; at other times, the difference was within the measurement error of $2 \mathrm{~cm}$. Given this measurement error, it is obvious that a WL difference of zero is indistinguishable from $\pm 1 \mathrm{~cm}$, necessitating an objective definition of a stand. Such a definition would essentially require identification of the threshold interval $I$, within which the changes in the observed water levels are small enough to be defined as imperceptible when compared with those generated from an idealized or standard $M_{2}$ tide. In order to fix the criteria, we proceed as follows:

- The tide in the SES is pre-dominantly semidiurnal. Therefore, a normalized sine curve with a range of $1 \mathrm{~m}$ and period 12:42 hours can be constructed to represent an ideal $M_{2}$ tide. This sine curve, sampled every 15 minutes represents a tidal WL variation that does not have a stand (figure 8). We use this synthetic $M_{2}$ curve as the standard against which to compare the normalized WL curves at the SES stations. These are normalized by dividing the observed WLs by the maximum WL observed at that station to give a tide curve with a maximum range of $1 \mathrm{~m}$. The WL differences computed between successive measurements for the standard $M_{2}$ curve are denoted by $\Delta_{\mathrm{SN}}$. Those for the normalized WL curves for the stations are denoted by $\Delta_{\mathrm{WN}}$.

- We define $I=[-0.01 \mathrm{~m},+0.01 \mathrm{~m}]$ as the threshold interval or band within which changes in the WL's are deemed to be imperceptible. The number of sampling/observation points for which $\Delta_{\mathrm{SN}}$ and $\Delta_{\mathrm{WN}}$ fall within $I$ are denoted by $D_{\mathrm{SN}}$ and $D_{\mathrm{WN}}$ respectively. For the standard $M_{2}$ synthetic sine curve, $D_{\mathrm{SN}} \leq 3$, which implies that the change in the water level can always be expected to be small over 30 minutes (for a 15-minute sampling interval) in the neighbourhood of HWs or LWs.

- Let $D_{I}=D_{\mathrm{WN}}-D_{\mathrm{SN}}$. For a stand, we must have $D_{I}>0$. The duration of the stand is then $15 \times D_{I}$ minutes. Note that the WL will remain quasistationary for 30 minutes more than this stand duration in the neighbourhood of $\mathrm{HW}$ or LW.

In other words, we say that a station has a stand if the change in WL between successive measurements is within $\pm 1 \mathrm{~cm}$ for the normalized curve for that station over 4 or more measurement intervals. This procedure is illustrated in figure 8 (panels c and $\mathrm{f}$ ). While $D_{I}$ is negative at B16 (figure $8 \mathrm{c}$ ), the slow change in the WL at R24, indicative of a stand, leads to a high value of $D_{I}(=10)$ giving a stand duration of $(150+30)=180$ minutes. Similarly, $D_{I}$ is 7 at S2 during LW3 (figure 8f), when a LW stand of 135 minutes is seen at the station, and is zero at S6, where no stand is seen during LW3. (Note that using rates of rise or fall instead of WL differences would lead to the same result because the rate would simply involve multiplying the WL differences by a constant factor. To account for the large change in range over the SES, a similar normalization would also be required. Hence, we have used WL differences in defining the stand.)

Stands of 30 minutes or more occurred at HW (figure 9a), during one or more tidal cycles at 27 of the 30 stations, the exceptions being M3 (Kalash), M26 (Canning), and B16 (Jharkhali Bali). The longest stands, with a duration exceeding 75 minutes (implying WL changes imperceptibly over more than 1 hour and 45 minutes), were seen in the northeastern part of the SES, i.e., on the Bidya, Gomdi, Harinbhanga and Raimangal. Stands during LW (figure 9b), were not as common, the most prominent of them occurring at S2 (Dhanchi), M26 (Canning), B23 (Pathankhali) and R29 (Sahebkhali). Thus, the observations show that a tidal stand can occur at a station during some tidal cycles and not during other cycles.

The long HW stands (figure 9a) occurred at stations at which the $M_{4}$ and $M_{6}$ constituents were large (figure 7 ). The $M_{2}$ tide was amplified by a factor of about 1.5 from mouth (Station S1, Indrapur) to the head (the Raimangal stations), but the $M_{4}$ and $M_{6}$ tides were amplified by a factor of about $4-5$. As has been speculated for other regions that exhibit a stand, it is possible that the stand in the SES is also due to the amplification of these higherfrequency constituents and is a type of asymmetry of the $M_{2}$ tide generated by the superposition on it of the $M_{4}$ and $M_{6}$ harmonics and a particular 
LW4-HW5-LW5, 20 March 2011

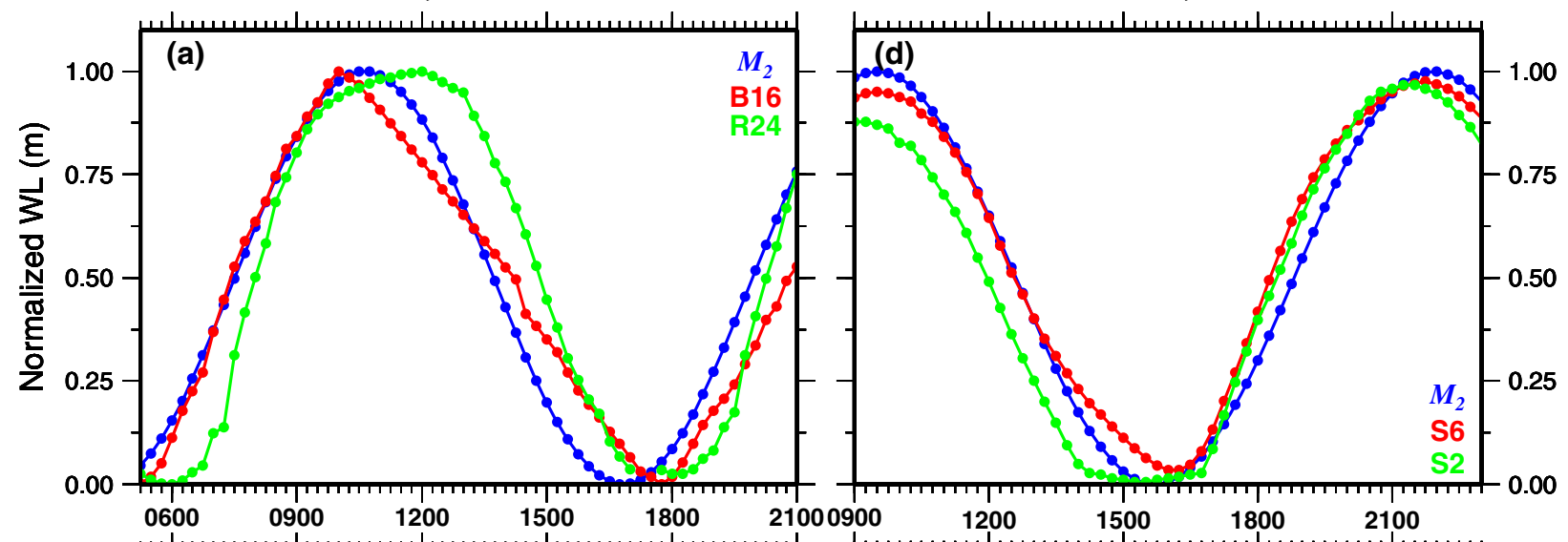

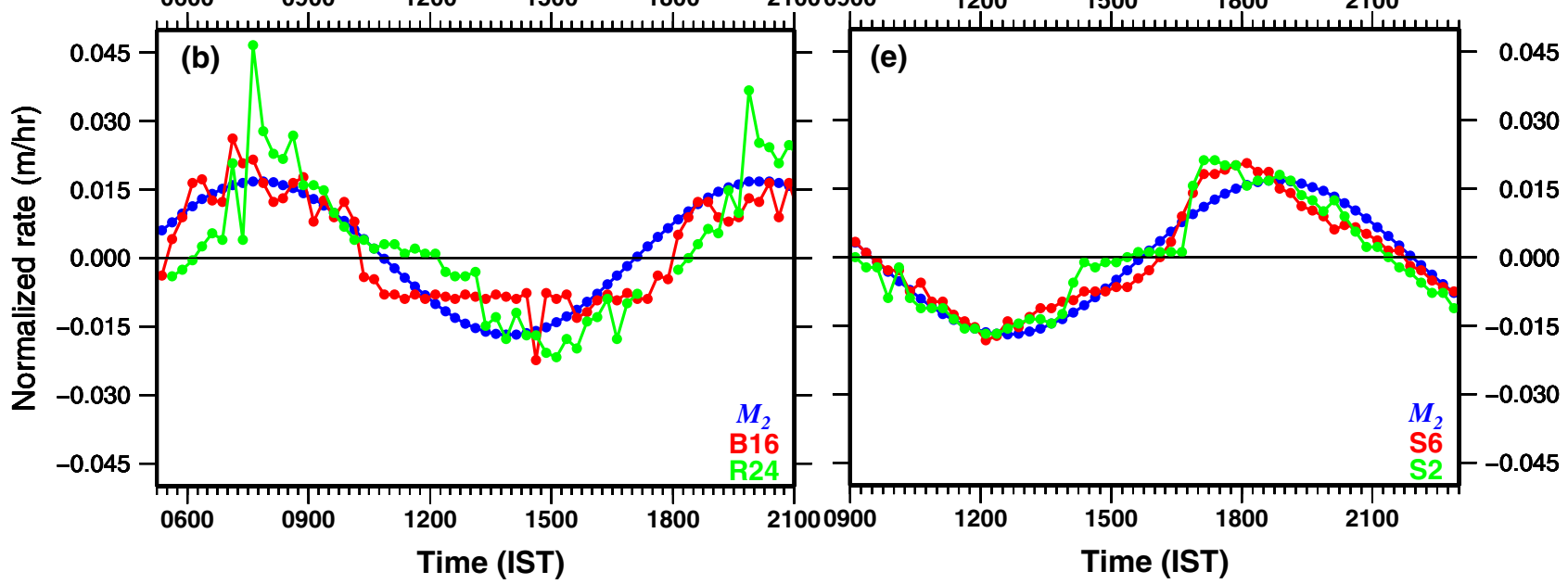
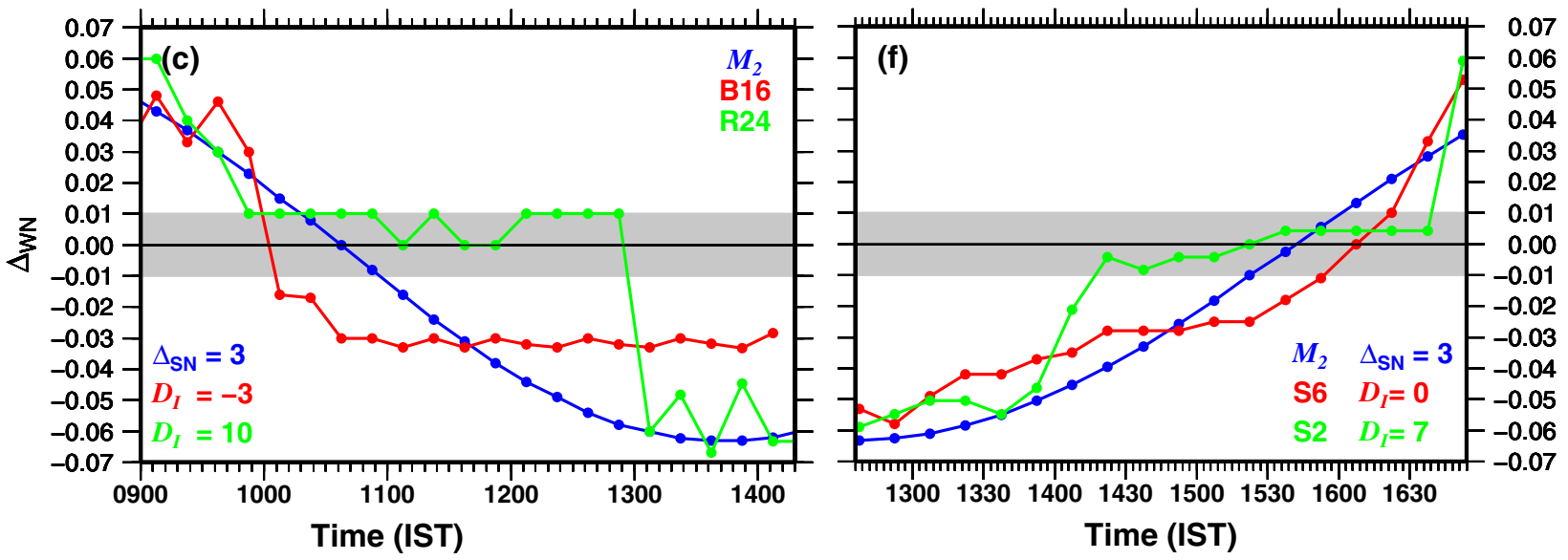

Figure 8. The tidal stand discussed in section 5. (a) The slow variation of the normalized water level (WL) during tidal cycle LW4-HW5-LW5 (morning to afternoon of 20 March 2011) at stations B16 (Jharkhali Bali) and R24 (Bagna), showing a stand during HW at R24 but not at B16. The WL variation due to a purely semi-diurnal tide is also shown for comparison. (b) The variations in the (normalized) rates (m/hour) corresponding to the WL variations shown in panel (a). The rate corresponding to the pure $M_{2}$ tide is also shown for comparison. (c) Identification of the Tidal Stand using the procedure outlined in section 5. The normalized WL differences $D_{\mathrm{WN}}$ during the HW stand corresponding to panels (a) and (b) are shown in this panel. The time axis covers a shorter duration than that in panels (a) and (b) in order to emphasise the changes around the HW mark. The grey band marks the numbers of observation when $D_{\mathrm{WN}}$ falls within the threshold interval $I=[-0.01 \mathrm{~m},+0.01 \mathrm{~m}] . D_{I}=D_{\mathrm{WN}}-D_{\mathrm{SN}}$, as defined in the text. Duration of the unusually slow changes in the water levels is $\left(D_{I} \times 15\right)$ minutes, plus the $\left(D_{\mathrm{SN}}-1\right) \times 15$ minutes over which these slow changes will normally occur for a pure $M_{2}$ tide. (d) As in panel (a), but for a LW stand during tidal cycle HW3-LW3-HW4 (morning to evening of 19 March 2011). A LW stand occurs at station S2 (Dhanchi), but not at S6 (Ramganga). (e) As in panel (b), but for the LW stand depicted in panel (d). (f) As in panel (c), but for the LW stand depicted in panel (a). 


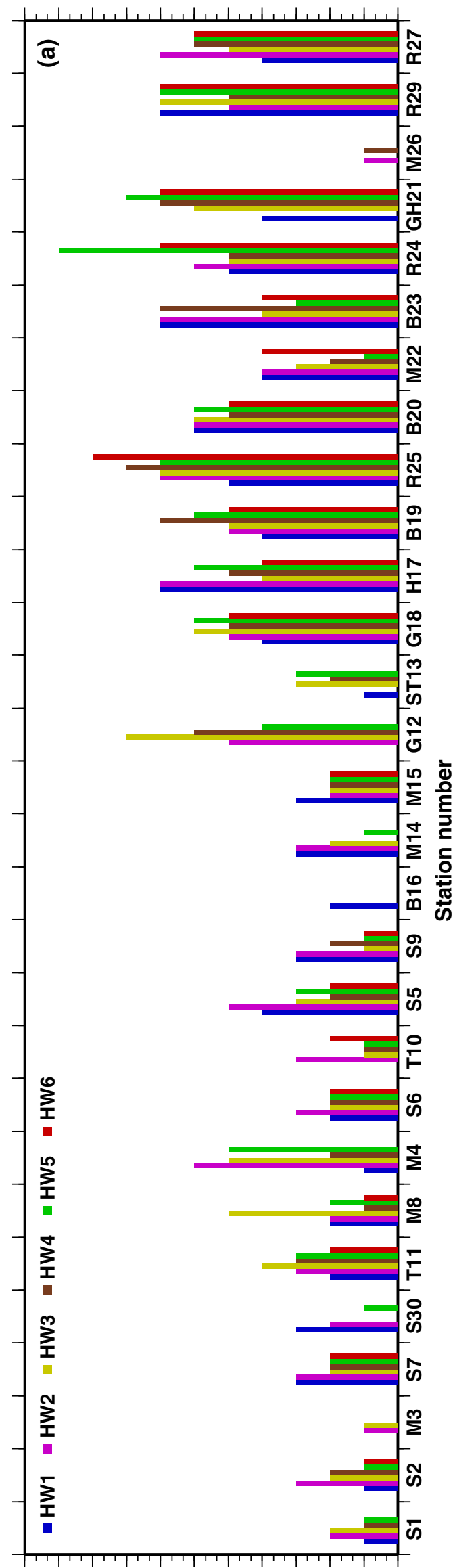

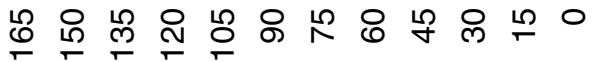
(sołnu!u) uo!̣ednp puejs MH

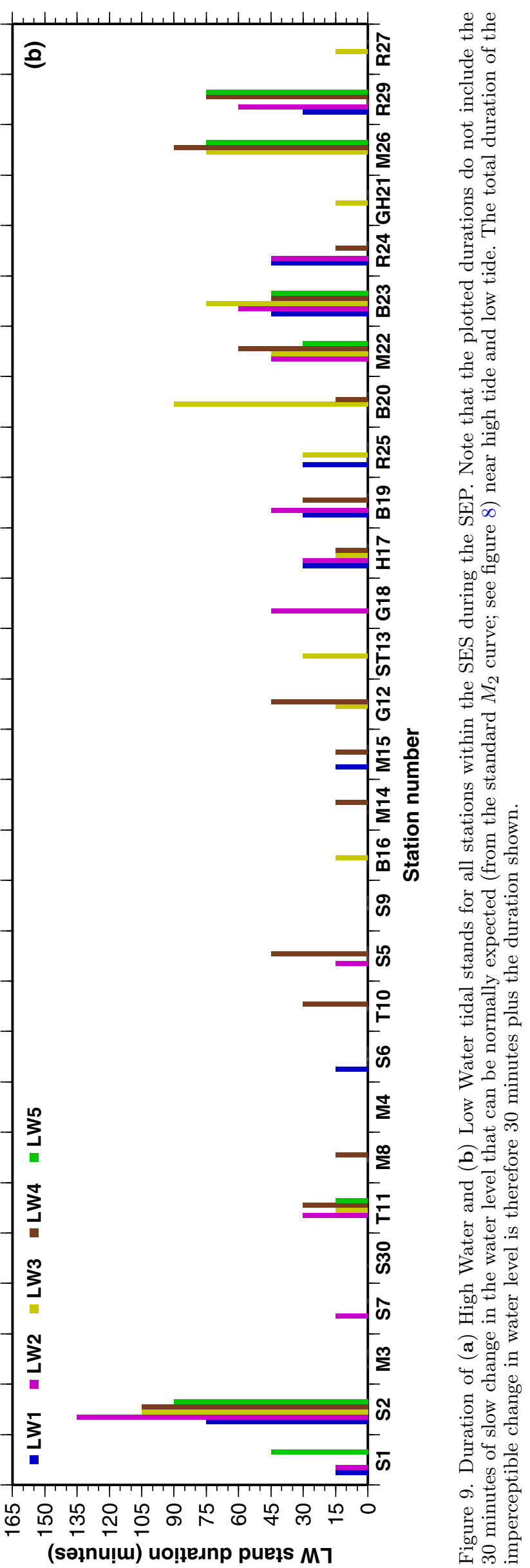




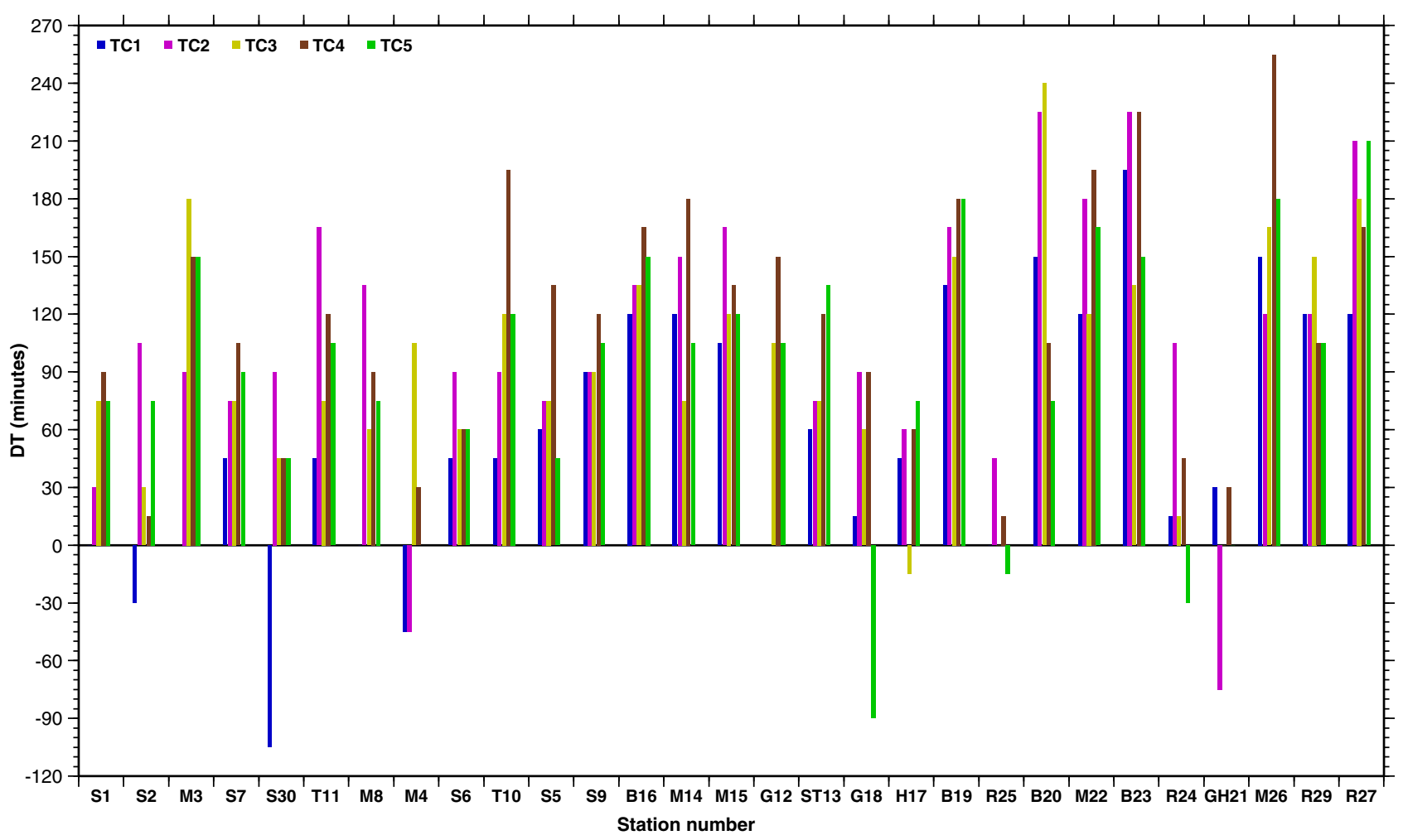

Figure 10. Tidal duration asymmetries within the SES. Plotted for five tidal cycles (TC) are the differences $D T$ (minutes) in the durations of fall and rise of the tide. A positive (negative) $D T$ implies flow (ebb) dominance. The tidal asymmetry vanished $(D T=0)$ at S1 and M8 (tidal cycle 1), GH21 (tidal cycles 3 and 5) and R25 (tidal cycles 1 and 3). Data were missing at M3 (tidal cycle 1), M4 (tidal cycle 5), and G12 (tidal cycles 1 and 2).

combination of the phases and amplifications of all three constituent bands.

The tidal stand modified significantly the tidal duration asymmetry in the SES. Tidal duration asymmetry is the inequality in the time intervals observed between the times of rise (from LW to the next HW) and fall (from HW to next LW) of the tidal water levels during a tidal cycle. The magnitude asymmetry of the tidal currents is a direct consequence of the duration asymmetry. A shorter (longer) duration of rise in the tide with a compensating longer (shorter) duration of its fall implies stronger (weaker) flood current and weaker (stronger) ebb current. For estuaries under a semidiurnal tidal regime, the essential features of tidal asymmetries are found to be well represented by the interaction of the M2 and $M_{4}$ constituents of the tide (Pingree and Griffiths 1979; Boon and Byrne 1981; Speer and Aubrey 1985; Song et al. 2011).

Ebb dominant tidal asymmetries are caused by the presence of upstream freshwater (Chugh 1961; Gole and Vaidyaraman 1967) and the presence and effects of tidal flats (Speer and Aubrey 1985; Friedrichs and Madsen 1992; Shetye and Gouveia 1992; Lanzoni and Seminara 1998, 2002;
Fortunato and Oliveira 2005). Ebb-dominant duration asymmetry has been observed in the Hoogly, the outer estuary of the SES, during the summer monsoon (Chugh 1961; Gole and Vaidyaraman 1967), and it is possible that it also occurs during the periodic freshwater releases from Farakka during December-June.

The SEP was conducted during the dry season, when the freshwater inflow is possible only from the Hoogly in the west and into the Raimangal in the east. Therefore, all the 30 stations exhibited a flow-dominant duration asymmetry (figure 10). At few stations, however, the flow dominance gave way to ebb dominance during some tidal cycles. In the flow-dominant cases, the difference between the durations of fall and rise ranged from 15 minutes to 4.25 hours; the ebb-dominant duration differences ranged from 15 minutes to 1.75 hours. Tidal duration asymmetries vanished at several stations: $\mathrm{S} 1$ and M8 (tidal cycle 1), GH21 (tidal cycles 3 and 5) and R25 (tidal cycles 1 and 3).

\section{Summary and discussion}

The observed variations of tidal water levels at 30 locations situated on various estuaries of the 
Sundarbans Estuarine System (SES) have been presented and discussed in this paper. It is for the first time that such data, consisting of continuous measurements of tidal elevations at 15-minute intervals over a 72-hour period, have been reported from this region. The observation stations, located on all the principal estuaries within the SES covered a wide range of conditions such as estuarine cross-sections, meanders, depths, and confluences with west-east channels.

The dominant semi-diurnal tide propagated to all parts of the SES (figure 5) with an overall northward amplification (figure 6). The first definite sign of decay was observed only at station R29 (Sahebkhali) on the Raimangal (figures 5 and 6). The lowest mean tidal range $(4.32 \mathrm{~m})$ among all 30 stations was observed at S2 (Dhanchi), while the highest $(6.73 \mathrm{~m})$ occurred at M26 (Canning) (table 2 ). The pattern of amplification was, nevertheless, complex because the SES consists of not only the south-north-flowing main channels, but also fairly big west-east-oriented channels connecting them. For example, the low tidal ranges and HW levels observed at S2 are possibly due to the interactions between the tidal wave propagating north up the Jagaddal and the westerly tidal inflow from the Thakuran through the Dhanchi Khaal (figure 3). Likewise, the tidal range was also low at M4 (Bonnie Camp; figures 5 and 6), which too was located in a connecting channel (figure 3 ).

In general, however, the tidal range increased from mouth to head, that is, the tidal wave amplified northwards. A simple explanation for this amplification can be given as follows. Channel geometry and frictional dissipation are the most important factors that determine the amplification or decay of a tidal wave as it progresses headwards along an estuarine channel. All the major estuaries in the SES are funnel-shaped; with widths decreasing rapidly headwards (northwards) from their mouths (section 1), i.e., they are convergent channels. This type of estuarine geometry has a 'funneling effect', which tends to amplify the tide as it propagates towards the head of the channel. Frictional dissipation on the other hand, tends to decrease this amplification. The northward amplification of the semi-diurnal tide observed in general in the SES channels therefore implies that, on an average, the geometric effect dominates over frictional dissipation in the SES.

Apart from this dominance of geometric effect over frictional dissipation, another likely cause of the amplification is the non-availability of adequate spill areas on either bank of the estuarine channels and the consequent inability of the heavily siltladen tide to dissipate itself completely. This condition exists mostly in the northern parts of the SES, where premature reclamation of land for human settlement and construction of protective embankments has gone on extensively and steadily since the mid-19th century. This has resulted in a progressive rise in the tidal levels over the years owing to raising of the channel beds by deposition of the tidal silt (Majumdar 1942). This so-called 'Heaping Up of the Tides' is observed to be most pronounced near Port Canning, situated on the narrowest part of the Matla and one of the earliest areas to be settled (Majumdar 1942). Observed Highest High Water Levels (HHWL) rose from $1.884 \mathrm{~m}$ in 1865 to $3.849 \mathrm{~m}$ in 1930 (Majumdar 1942). In the present study, the HHWL observed at Canning was $7.08 \mathrm{~m}$ (figure 5, table 5), a near doubling from 1930. This increase in HHWL can be attributed to the blockage of most of the spill area of the Matla, known as the Salt Lake Marshes, which once extended northwest from Port Canning right up to the east of the city of Kolkata. Reclaimed and settled under the huge population pressure faced by West Bengal following India's independence, the Salt Lake Marshes have been completely built up and at present form the part of Greater Kolkata known as Salt Lake City.

The observations show that the semi-diurnal $\left(M_{2}\right)$ amplitude roughly doubled from mouth to head, but there was no such amplification of the diurnal band. The amplification was maximum for the 4-hourly $\left(M_{6}\right)$ and 6-hourly $\left(M_{4}\right)$ tidal constituents (figure 7 ), which amplified by a factor of about 4-5. Other constituents were weaker.

In most of the locations in the SES, the tide was found to be a superposition of the $M_{4}$ and $M_{6}$ bands on the dominant semi-diurnal $M_{2}$ band. As discussed earlier (sections 4 and 5) nonlinear effects, for example, the interaction of the semidiurnal tide with the bottom of the channel (nonlinear friction), can lead to the generation of the higher harmonic bands such as the $M_{4}$ and $M_{6}$, which amplify as the tide progresses headward along the channels. Depending on the amplitude and the phase of a harmonic, such a superposition leads to the tidal asymmetries. The flood-dominant and ebb-dominant duration asymmetries observed at the SES locations are the best known examples of such tidal asymmetries.

The shortest time of rise (strongest flow current) recorded was 4 hours at B20 (Rangabelia) during LW3-HW4 and at M26 (Canning) during LW4HW5. At some stations during some tidal cycles, however, the flow dominance gave way to ebb dominance. The shortest duration of fall (strongest ebb current) was 5 hours 15 minutes at S30 (Shibganj) during HW1-LW1. Well-known causes of ebb dominance in tidal estuaries are the presence of upstream freshwater and tidal flats. Tidal 
flats exist extensively throughout the SES, but the transient nature of the change over to ebbdominance from flow-dominance observed at only a few stations on the Saptamukhi over single tidal cycles suggest that the presence of freshwater is the most likely cause of this transition. The possible source of freshwater in the western channels may be inflow from the Hoogly via connecting west-east channels during the periodic discharge of freshwater at Farakka. In the east, the Raimangal receives freshwater from the Ganga via the Ichhamati.

This duration asymmetry has practical consequences. The flow dominance implies strong flow tidal currents and the inward transport of sediment from the mouth of the estuaries, which has an impact on estuarine morphology (Speer 1984; Dronkers 1986; Friedrichs and Aubrey 1988; Speer et al. 1991).

The tidal duration asymmetry is significantly affected in the SES by the tidal stand that was observed at most stations. WL changes imperceptibly during a stand, but this slow change is distinct from the slow change of 30 minutes (three successive observations) that normally occurs near the crest and trough of a sinusoidal curve (figure $8)$. We provide an objective definition of a stand: a station has a stand if the change in WL between successive measurements is within $\pm 0.01 \mathrm{~m}$ for the normalized WL curve for that station over four or more measurement intervals. If the stand duration thus estimated is 30 minutes, WL changes slowly for a total of 60 minutes around the HW or LW level. HW stands were common in the SES (figure 9a), but LW stands also occurred at a few stations during some tidal cycles (figure 9b). The duration of the HW stand was found to vary from 15 to 150 minutes. The longer stands are observed at the northeastern stations. Only a few stations did not exhibit a HW stand; notable among these stations are Canning (M26), which had the highest tidal range and B16 (Jharkhali Bali). At B16, the normalized water-level differences between consecutive observations near the HW/LW peaks were consistently found to exceed the prescribed threshold of $\pm 0.01 \mathrm{~m}$, implying higher rates of rise and fall of the WL near HW and LW.

While it is possible that the tidal stand observed in most of the SES locations represents another type of asymmetry of the tide, the observations show that flow-dominant tidal duration asymmetries exist over most tidal cycles at all the SES locations, but tidal stands, particularly the LW stands, may or may not exist at a location. An extreme case is the vanishing of tidal asymmetries at some of the locations over some tidal cycles: S1 and M8 (tidal cycle 1), GH21 (tidal cycles 3 and 5), and R25 (tidal cycles 1 and 3). Although the tide in such cases is symmetric, in that the duration is the same for rise and fall, HW tidal stands of considerable duration exist during these cycles at these locations (figure 9a). Another exception is B16 (Jharkhali Bali) which does not have a HW (LW) stand, except during the first (third) tidal cycle, but has significant flow-dominant asymmetry for all tidal cycles. These exceptions imply a need to distinguish the tidal stand from the tidal asymmetry: while they may have much in common, the observations suggest that they are distinct phenomena.

The engineering implications of a tidal stand are obvious. One key impact is in the increase a stand implies in the flow or ebb dominance at a station, leading to stronger flow or ebb currents. If the ebb currents are strong, then there is possibility of scouring near the jetty piers during a LW stand. It is the more common HW stand, however, that is probably a more serious threat. Stations like Bagna (R24) commonly have HW stands of duration 75 minutes or more; a 75-minute stand implies that the WL changes slowly around the HW mark over 1 hour and 45 minutes instead of the usual 30 minutes (for a pure $M_{2}$ tide). This 'wall of water' develops twice a day at several stations in the SES, increasing the chance of a surge due to a storm coinciding with the high tide. A long stand also leads to a jump in the rate of change of WL, even if for a short duration (figure 8b). An example of the possible impact of the stand is the repeated destruction of the Forest Department jetty at Bagna, leading to the abandonment of any further attempts at constructing a permanent jetty there. This problem has generally been attributed to the tidal range at Bagna being higher than at other locations. As the data show, however, the range at Bagna is actually lower than the range at several other stations (figures 5 and 6 ). We conjecture that it is the long HW stands that make Bagna and other neighbouring stations on the Raimangal more prone to destruction by surges.

Storm surges have periods ranging from a few hours to a day. It is likely that a surge whose period is around 4-6 hours will amplify considerably as it propagates inland, just as do the $M_{4}$ and $M_{6}$ tides with the same periodicities. Such a surge would have a higher potential for destruction.

The ubiquity of stands in the SES and the considerable variation in its duration makes the SES an interesting laboratory for studying this tidal phenomenon, which, apart from being poorly understood, possibly has a significant influence on the life of the inhabitants of this tidal country. The SES, with its remarkable geometry of interconnected channels and the tidal stand, presents a challenge for estuarine modelling. 


\section{Acknowledgements}

This work was conducted as part of the research project at SOS, JU (Sanction No. F/INCOIS/INDOMOD-11-2007/2691 dated December 20, 2007) funded by INCOIS, Ministry of Earth Sciences, Government of India, under the INDOMOD programme. The authors gratefully acknowledge the following organizations and people whose encouragement and active cooperation led to the successful implementation of the Sundarbans Estuary Programme: The Indian National Centre for Ocean Information Services (INCOIS), Ministry of Earth Sciences, Government of India, for funding the programme; the Department of Forests and the Sundarbans Development Board, Government of West Bengal for permission to work in some of the Reserve Forest areas, accommodation and other facilities; the Tagore Society for Rural Development (TSRD), Sabuj Sangha (SS), and the Calcutta Wildlife Society (CWS) for providing local man power and logistic support; the Border Security Force (Eastern Frontier), Government of India, and the West Bengal Police for providing security during the observation period. The SEP, initiated at the suggestion of Dr S R Shetye, in September 2010, progressed rapidly to a full fledged programme by March 2011 under the constant and enthusiastic encouragement received from him, Dr S S C Shenoi, and Prof. A D Mukherjee. Dr M Ravichandran was always ready with his cooperation throughout the preparatory and implementation stages of the programme. The authors gratefully acknowledge Dr A C Anil, Dr Dileep Kumar, Dr A S Unnikrishnan, and Dr V Gopalakrishna of CSIR-NIO, Goa, and Dr V V S S Sarma, Dr V S N Murty and Dr Y Sadhuram of CSIR-NIO Regional Centre, Visakhapatnam for their valuable suggestions and help in using the Autosal facilities. C Gokul helped with the figures. They extend their sincere thanks to the local coordinators, Mr Kanai Lal Sarkar (TSRD), Mr Swapan Kumar Das and Mr Angshuman Das (SS), Mr Nihar Mandal (CWS), and the Scientific Supervisors: Mr Manik Maity, Mr Nanda Gopal Maity and Mr Sumit Koley from Digha; Mr Jayanta Sutradhar, Mr Joydeep Ghosal, Mr Prasanta Nandi, Mr Pranab Kumar Mukherjee, and Mr Shantanu Paramanik from Purulia; and Mr Dwaipayan Chakraborty. The help and support provided by Mr Kalyan Mallick, then Commandant, 8th Battalion, Eastern Frontier Rifles, Mrs Rupa Ravindran, and Mr Indrajit Sarkar was truly immense. MC and GKS would like to specially acknowledge the cooperation extended to them by Dr M Bardhan Roy (Principal, Basanti Devi College) and Prof. Sugata Hazra (Director, SOS, JU) during the preparatory and final stages of the SEP. Finally, the authors sincerely thank and gratefully acknowledge each and every one of the 180 observers, the 30 local supervisors, the pilots of the 44 mechanized boats and their assistants, for the dedication and sincerity with which they performed their work, mostly under difficult and dangerous conditions. Their contribution towards the effectiveness and success of the SEP was immeasurable. This is NIO contribution 5329 .

\section{Appendix 1}

\section{A1.1 The Hoogly}

Logistic considerations prevented us from undertaking tidal observations on river Hoogly during the SEP. Nevertheless, for the interested reader, we give here a brief description of this most wellknown and best studied of the SES estuaries, gleaned from the references cited in this section, particularly, Chugh (1961), Gole and Vaidyaraman (1967) and Parua (2010) and other articles and websites, too numerous to mention. The various rivers and places mentioned in the course of this description can all be located in the schematic (figure A1) showing the course of the BhagirathiHoogly.

River Hoogly $\left(21.517^{\circ}-23.333^{\circ} \mathrm{N}, \quad 87.75^{\circ}-\right.$ $88.875^{\circ} \mathrm{E}$ ) originates as the combined stream of the rivers Bhagirathi, Jalangi, and MathabhangaChurni near Nabadwip $\left(23.42^{\circ} \mathrm{N}, 88.37^{\circ} \mathrm{E}\right)$. This river, approximately $350 \mathrm{~km}$ long, enters the Bay of Bengal at Sagar Island $\left(21.56^{\circ}-21.88^{\circ} \mathrm{N}, 88.08^{\circ}-\right.$ $\left.88.16^{\circ} \mathrm{E}\right)$ through an almost $25 \mathrm{~km}$ wide, funnelshaped mouth. The semi-diurnal tides entering the Hoogly propagate up to Nabadwip, nearly $290 \mathrm{~km}$ north of the seaface. The tidal range at Sagar $\left(21.65^{\circ} \mathrm{N}, 88.05^{\circ} \mathrm{E}\right)$ varies between 4.24 and $5.19 \mathrm{~m}$ and increases up to 5.3-6.1 $\mathrm{m}$ at Diamond Harbour $\left(22.192^{\circ} \mathrm{N}-88.185^{\circ} \mathrm{E}\right)$. The tidal wave begins to decay after this, ranging between 3.88 and $4.78 \mathrm{~m}$ at Garden Reach within the Calcutta Port area, and to $0.16-0.35 \mathrm{~m}$ at Samudragarh $\left(23.37^{\circ} \mathrm{N}, 88.256^{\circ} \mathrm{E}\right)$, about $250 \mathrm{~km}$ north of Sagar. During the summer monsoon, additional freshwater discharges enter the Hoogly from the rivers Damodar, Rupnarayan, Haldi, and Rasulpur at their outfalls located at different points in the last stretch between Kolkata (Calcutta) and Sagar. During the lean period, however, navigability of the river depends heavily on the periodic release of Ganga waters through the barrage at Farakka $\left(24.8^{\circ} \mathrm{N}, 87.9^{\circ} \mathrm{E}\right)$.

Till the 15th century, the Bhagirathi-Hoogly was the course followed by the Ganga flowing into the Bay of Bengal. Owing to geological reasons, the Ganga gradually shifted eastward, so that by 


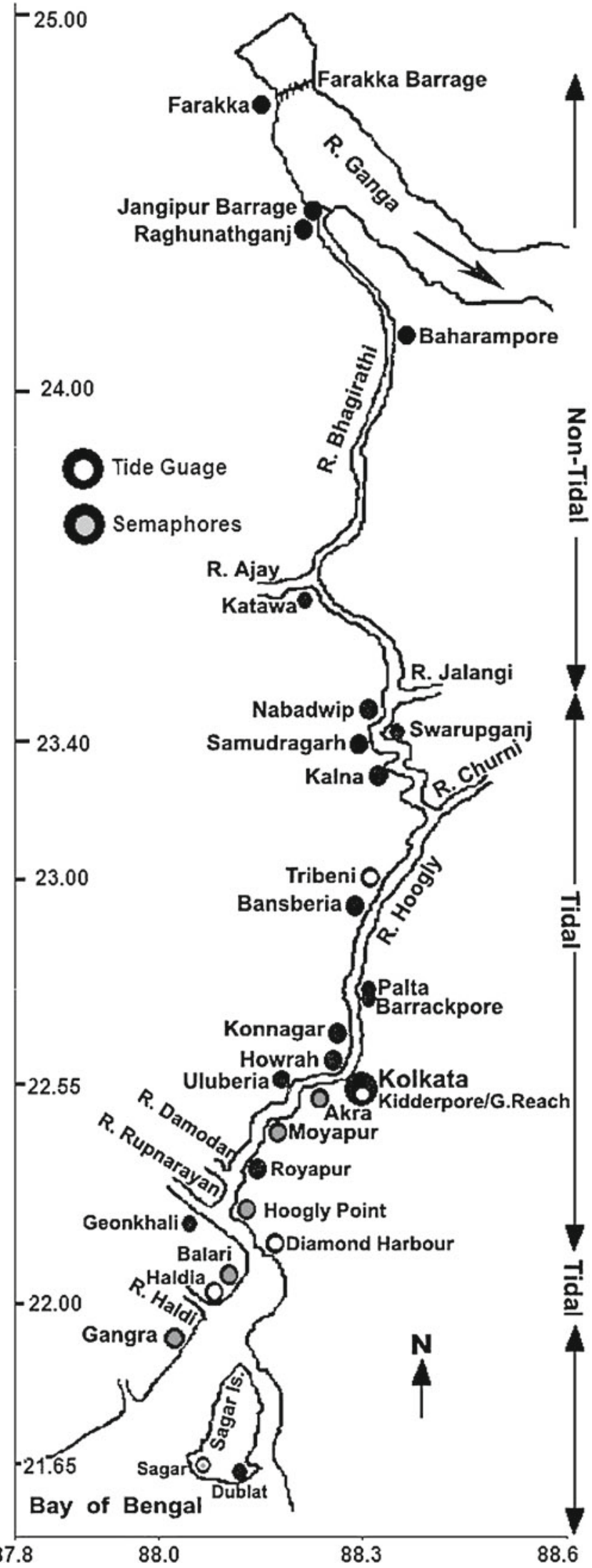

Figure A1. A schematic representation of the BhagirathiHoogly river system. Longitudes (latitudes) along the horizontal (vertical) axis are in ${ }^{\circ} \mathrm{E}\left({ }^{\circ} \mathrm{N}\right)$. the 16th century, the Bhagirathi-Hoogly became the first deltaic distributary of the river. Although not significantly observed till the late 19th century, the effects of the subsequent reduction in the Gangetic flow through the Bhagirathi-Hoogly was a gradual silting up of the Bhagirathi at its offtake point near Farakka and a loss of navigability of the Hoogly.

The Bhagirathi-Hoogly had always been an important shipping route used for trade between India and the rest of the world. It was, however, the phenomenal development in the 18th century of the Port and Metropolis of Calcutta $\left(22.548^{\circ} \mathrm{N}\right.$, $88.301^{\circ} \mathrm{E}$ ), that further increased the importance of the river, making it a well-known name globally. Situated on the east bank of the Hoogly about $145 \mathrm{~km}$ north of its mouth at Sagar Island, Calcutta (now known by its original name, Kolkata), the erstwhile capital of British India (1772-1912) and the second largest city in the British Empire, is at present the most densely populated city in India. The Port of Calcutta, the then most important international port serving a vast Indian hinterland and the Asian colonies of the British Empire (Bayly 1985; Ray 1990; Tan 2007), is still one of the major ports of India, but with a much reduced hinterland consisting of northeast India, parts of north and east India, and the countries of Bhutan and Nepal.

From the very beginning of its establishment in the late 18th century as a port of call for deep draft vessels, the Port of Calcutta has suffered constantly from the problem of loss of navigability due to the reasons mentioned above. The consequent reduction of the cubic capacity of the channel, formation of sandbars, particularly in the southward stretch from Garden Reach to Sagar, and the shoaling of various stretches, further aggravated the problem. Meandering over nearly $46 \%$ of its length, the geometry of the Hoogly estuarine channel is made more complicated by the existence of as many as 10 shifting sandbars that exist in the $70 \mathrm{~km}$ stretch between the Port of Calcutta and Diamond Harbour lying to its south. Constant changes are observed in the tidal axes, bank-line migrations, and erosion in various sections of the river. These changes and associated sediment load movements make the Hoogly a very dynamic estuary (Gole and Vaidyaraman 1967; Parua 2010).

This dynamism has also been the main reason for the regular monitoring of the hydrological and morphological characteristics of the river over a long time. The Port Authorities (the Commissioners for the Port of Calcutta in British India and the Calcutta Port Trust in Independent India) have maintained tide-gauge stations (see figure A1) at Sagar/Dublat $\left(21.633^{\circ} \mathrm{N}, 88.133^{\circ} \mathrm{E}\right)$ from 1881-1886, and again from 1944 onwards, Diamond 
Harbour (1875-1886, then 1947 onwards) and at Garden Reach/Kidderpore $\left(22.533^{\circ} \mathrm{N}, 88.317^{\circ} \mathrm{E}\right)$, lying within the Calcutta Port area, from 18811932 and 1932 onwards. Automatic tide gauges for continuous monitoring of tidal levels now function at Tribeni $\left(22.938^{\circ} \mathrm{N}, 88.4^{\circ} \mathrm{E}\right)$, Garden Reach, Diamond Harbour, and Haldia. Semaphores for displaying the rises of tide are operational at the sand bars at Akra $\left(22.5^{\circ} \mathrm{N}, 88.25^{\circ} \mathrm{E}\right)$, Moyapur $\left(22.417^{\circ} \mathrm{N}, 88.117^{\circ} \mathrm{E}\right)$, Hoogly Point $\left(22.217^{\circ} \mathrm{N}\right.$, $\left.88.083^{\circ} \mathrm{E}\right)$, Balari $\left(22.067^{\circ} \mathrm{N}, 88.150^{\circ} \mathrm{E}\right)$, Gangra $\left(21.950^{\circ} \mathrm{N}, 88.017^{\circ} \mathrm{E}\right)$ and Sagar. The tide-gauge data are supplied to the Survey of India, the agency responsible for predicting and preparing tide tables for the six Standard Ports on the Hoogly, namely, Sagar, Gangra, Haldia, Diamond Harbour, Moyapur, and Garden Reach.

The earliest tidal observations in the Hoogly were recorded during $1805-1828$ at Calcutta by Kyd (1829). This was for the first time that 24hour tidal curves for a full year, 1823-1824, the highest high water and lowest low water levels for each year during 1806-1828, and the high and low water levels at each lunar phase during 1806-1807 and 1825-1826 were documented.

Oag (1939) was perhaps the first to identify the three distinct seasonal patterns in the tides in the Hoogly. During the summer (pre-monsoon) 'dry period' of March-June, flood-tide effects dominate over the ebb tide. During the monsoon or 'wet period', July-October, freshwater discharges in the upstream areas of the Ganga and ebb-tide effects dominate. Owing to the banking of the freshwater in the Ganga during the summer monsoon, the dominance of the ebb tide continues even during the post-monsoon months (November-February).

During 1853-1968, hydrological studies on the Hoogly were conducted by as many as 16 Expert Committees set up by the Government of India, with the primary objective of studying and improving the rapidly deteriorating navigability of the river and the port. The findings of these committees (summarized in Parua 2010) inevitably led to their recommendation of increasing the upland supply of freshwater to the BhagirathiHoogly during the lean seasons by diverting at least 40,000 cusecs of Gangetic freshwater through a suitably constructed barrage across the Ganga. The recommendations were finally implemented with the beginning of the construction of the barrage at Farakka in 1960 and its commissioning in 1975. The first diversions of freshwater from the Ganga following the recommended manner, during the 1976 lean season, had the immediate effect of completely flushing out the Hoogly (Nandy et al. 1983; Sinha et al. 1996) and considerably improving the overall state of the river.
Thus, the Hoogly provides an outstanding example of the resuscitation of an estuary from its moribund state by the application of modern engineering technology firmly based on the scientific understanding of river dynamics.

Chugh (1961) made a thorough study of the tidal characteristics of the Hoogly based on the long tide-gauge records for 1881-1959 from Sagar, Diamond Harbour, and Garden Reach. The study revealed that tidal parameters such as the lunitidal intervals (the diurnal inequality), mean high and low water levels, mean tidal levels, and tidal ranges and the mean river levels all went through seasonal changes during this period. The various tidal planes were found to have changed differently, indicating changes in the tidal regimes and reflecting changes in the conditions of the river bed. Annual variations of the mean sea levels at Sagar and Diamond Harbour were found to be insignificant in comparison to the observed annual variations of the mean river levels at Garden Reach during this period. This low variability was attributed to the variations in depth and other conditions in the river.

Monthly mean high water levels at Garden Reach were found to have changed considerably since 1882. The Highest High Water level recorded here was $8.03 \mathrm{~m}$ (in August 1890) and $8.07 \mathrm{~m}$ (in October 1959). The Lowest Low Water level of $0.54 \mathrm{~m}$ observed by Kyd (1805-1828), remained the minimum level till 1919, after which it decreased to $0.5 \mathrm{~m}$ as observed in 1935, 1936, and 1949 . A steady increase in the Mean, Spring and Neap Tidal ranges at Garden Reach was observed during the years 1882, 1949-1953 and 1953-1959. Since it could be confirmed that no changes in the mean sea levels occurred during this period, this increase could be attributed to the widening and deepening of the mouth of the river, which were undertaken to improve its navigability.

During the freshet season (the summer monsoon 'wet period'), the tidal limit moved down south of Swarupganj $\left(23.448^{\circ} \mathrm{N}, 88.428^{\circ} \mathrm{E}\right)$ to Kalna $\left(23.22^{\circ} \mathrm{N}, 88.37^{\circ} \mathrm{E}\right)$. It was also found that if the strength of the freshets were adequate enough, Calcutta experienced continuous ebb during neap tides. Up to Garden Reach, lower tidal ranges occurred at the beginning of the freshet months May-June, followed by a sharp increase. However, tidal ranges remained low at Bansberia $\left(23.034^{\circ} \mathrm{N}\right.$, $\left.88.378^{\circ} \mathrm{E}\right), 50 \mathrm{~km}$ north of Calcutta, during the entire freshet season. The lowest tidal ranges in the Hoogly occurred during the maximum flood years: $0.48 \mathrm{~m}$ in $1823,0.99 \mathrm{~m}$ during 1910 and $1938,2.07 \mathrm{~m}$ in 1956 , and $1.59 \mathrm{~m}$ in 1959. These were also the years of unprecedented floods, during which the highest Low Water levels of 6.1, 3.27, $3.51,3.27$ and $3.68 \mathrm{~m}$, respectively, were observed. 
The Hoogly is also one of the few rivers in the world that experiences bore tides (Chugh 1961; Gole and Vaidyaraman 1967; Pugh 1987; Chanson 2001; Parua 2010), as a result of the combination of the large tidal ranges and the low (around $6.5 \mathrm{~m}$ ) channel depths that occur specially during the lean-periods. Appearing first about $40 \mathrm{~km}$ south of Calcutta around Royapur $\left(22.291^{\circ} \mathrm{N}, 88.304^{\circ} \mathrm{E}\right)$, soon after low water is reached there, the tidal wave increases rapidly in height and travels northwards up to Konnagar $\left(22.7^{\circ} \mathrm{N}, 88.35^{\circ} \mathrm{E}\right)$, approximately $14.5 \mathrm{~km}$ north of Calcutta, as a $4-5 \mathrm{~m}$ high wall of water with a typical speed of about $9 \mathrm{~m} / \mathrm{s}$ (Chugh 1961). The time taken by the bore to reach the maximum height ("the break of the bore') is typically, 32 minutes from the time of low water.

Before the construction of the barrage at Farakka, the incidence of bore tides in the Hoogly increased (table A1) and they were also observed to occur throughout the year. This increase in the frequency of occurrence of bores was a result of the progressive reduction in the supply of freshwater in the upstream reaches of the river, leading to continuously decreasing channel depths during the lean periods, and the narrowing of the channel in some sections. By the end of 1976, the effect of freshwater discharges from Farakka during the dry period began to manifest itself and the number of tidal bores decreased rapidly.

Changes in the salinity of the estuary follow the seasonal tidal pattern, with increased salinity observed during the pre-monsoon dry period and decreased salinity during the monsoonal wet period (Oag 1939; Gole and Vaidyaraman 1967). The Central Inland Fisheries Research Institute, in their biological observational studies (Rao 1969; Nandy et al. 1983; Sinha et al. 1996; Das and Samanta 2006), have followed the practice of dividing the entire tidal stretch of the Hoogly into three zones based on the existing salinities: An Upper Freshwater Zone, a Middle or Estuarine Zone (salinity range: trace values to $12.68 \mathrm{psu}$ ), and a Lower or Marine Zone (salinity range: $4.32-29.77 \mathrm{psu}$ ). The extent of each of these zones varies seasonally and

Table A1. Tidal bores observed on the Hoogly during 1935-2000 (after Parua 2010).

\begin{tabular}{llc}
\hline Year & \multicolumn{1}{c}{ Months } & Number \\
\hline 1935 & March-May & 20 \\
1974 & January-June & 88 \\
& July-December & 51 \\
1998 & January-June & 11 \\
& July-December & 6 \\
$1999-2000$ & January-June & 6 \\
\hline
\end{tabular}

annually, depending on the strength of the freshets received in the upstream parts of the river.

Increased salinity in the Hoogly, again a result of reduced upstream freshwater, became a grave concern during the late 1950s and throughout the 1960s (Parua 2010). The freshwater from the river has been the only source of drinking water supplied to Calcutta and adjoining areas and has been used heavily by the industries and thermal power generation plants lining both banks of the river. The dry-period salinity levels, monitored regularly since 1865, at the intake point at the Water Works at Palta $\left(22.783^{\circ} \mathrm{N}, 88.370^{\circ} \mathrm{E}\right), 24 \mathrm{~km}$ north of Calcutta, rose steadily from $\sim 0.05 \mathrm{psu}$ in 1900 to $0.19-0.65$ psu during $1915-1957$ and 1.0381.5 psu during 1960-1975, far above the potable limit of $0.5-1.0$ psu prescribed by the World Health Organization. The corrosion and scaling of boilers and other machinery by the highly saline water affected the smooth functioning of the industries, power generation units and even in the running of the railways all throughout this period. Impacts were also considerable on the agricultural sector. Post-Farakka dry-period salinity values at Palta showed a rapid decrease from $1.5-0.2 \mathrm{psu}$ during 1975-1980 to $0.2-0.167$ psu during 19801985. Values during 1990-2000 (0.2-0.236 psu), however, have again started to show an upward trend.

A comparative study of ecological changes in the Hoogly during pre- and post-Farakka periods (Nandy et al. 1983; Sinha et al. 1996) documented the immediate effect of the freshwater released on the salinity observed in the different stretches of the Hoogly. In general, the salinity decreased over the entire estuary. The $54 \mathrm{~km}$ stretch of the Hoogly between Kalna and Barrackpore $\left(22.76^{\circ} \mathrm{N}\right.$, $88.37^{\circ} \mathrm{E}$; approximately $23 \mathrm{~km}$ north of Calcutta), identified during 1960-1961 as the freshwater zone, was extended downstream during 1975-1976 and 1976-1977 by a further $30 \mathrm{~km}$ up to Uluberia $\left(22.47^{\circ} \mathrm{N}, 88.11^{\circ} \mathrm{E}\right)$. The true estuarine zone was shifted $40 \mathrm{~km}$ down south to Geonkhali $\left(22.2^{\circ} \mathrm{N}\right.$, $88.05^{\circ} \mathrm{E}$ ), near the confluence of the rivers Hoogly and the Rupnarayan (figure A1), and the marine zone was pushed out further south to Kakdwip $\left(21.85^{\circ} \mathrm{N}, 88.2^{\circ} \mathrm{E}\right)$ and into the Bay of Bengal.

Observational studies on the chemical and biological characteristics of the Hoogly (Roy 1949a, 1955; Dutta et al. 1954; Bose 1956; Shetty et al. 1961; Basu and Ghosh 1970; Saha et al. 1971; Mukhopadhyay et al. 2002; Sadhuram et al. 2005; Mukherjee et al. 2006; Manna et al. 2010) have mostly accounted for tidal influences by taking and comparing the observations during high and low tide periods. Remotely sensed data have been used for studying erosion/accretion at Sagar, the largest island in the Hoogly (Jayappa et al. 2006; Dinesh 
Kumar et al. 2007). Pollution of the coastal waters of the Sundarbans has also been investigated, again as localized studies (Ganguly et al. 2006, 2007; Mukherjee et al. 2010).

\section{A1.2 The Saptamukhi and Matla}

As mentioned in their publication CS(AR) 21/9697 (Jha et al. 1999), an extensive hydrological survey of the southern stretch of the river Saptamukhi was carried out during 1961-1963 by the National Institute of Hydrology, Roorkee. The flood volume of the combined Saptamukhi East and West Gullies at the seaface was estimated to be of the order of 43750, 500, and 200 cumecs during the Spring, Mean, and Neap phases, respectively, with the SEG carrying the major portion of the inflow from the Bay. At the tip of the Bara Rakshaskhali Island (figures 2 and 3 ), the mean flow was estimated to be of the order of 30 cumecs, about $6 \%$ of the flood flow at the mouth. Following this, no such surveys have been undertaken to the best of our knowledge.

Salinities at Port Canning on the Matla have been measured by several researchers. Variations between 10.72 and 30.41 psu during 1962-1963 and 1965-1966 were reported by Rao (1969).

It is known that the twice-daily mixing of the estuarine waters by the tides causes changes in its sediment load, salinity, nutrient, and pollutant content, all of which have an impact on the biodiversity, biological, and chemical characteristics of the estuaries. These latter characteristics are by far, the most studied aspects of a few of the inner estuaries of the SES (Guha Bakshi et al. 1999; Naskar and Mandal 1999; Naskar 2003; Mukherjee and Sen 2008; Mukherjee et al. 2008; Mandal et al. 2009; Manna et al. 2010).

\section{Appendix 2}

\section{A2.1 The Visual Tide Staff}

The Visual Tide Staff (VTS) or Tide Pole (figure A2a, h and i) was used to measure tidal water levels because of the simplicity involved. This instrument, and other observational procedures used in the SEP, exactly follow those used in a similar study of the Mandovi-Zuari Estuaries (Shetye et al. 1995, 1996, 2007; Sundar and Shetye 2005).

Qualitative information regarding tidal levels and the duration of high and low water at particular locations were collected from local residents during the reconnaissance trips. Heights of jetties, wherever they existed, were noted along with the levels of saline depositions on the mangroves covering the estuarine banks; the latter observations were made whenever convenient. This information allowed us to estimate approximately the expected levels of high/low waters and tidal ranges at the selected observation stations.

In order to accommodate the high tidal ranges $(>7 \mathrm{~m})$ observed at some of the locations, the VTS had to be at least 7-8 $\mathrm{m}$ above the estuarine low water levels. Everywhere in the Sundarbans, and specifically in the banks of the estuaries or any other water channel, the soil is soft clayey mud (figure A2b, c and i). To install the long and narrow ( 2 or 3 inches in diameter) tide pole in a vertical position and make the installation strong enough to withstand the impact of the tidal waves and high winds, a good length of the pole had to be sunk deep into the mud. Construction of a concrete or brick base had to be ruled out, particularly at the forward locations because the heaviness of the construction would make it sink into the mud.

The tide poles used for observations in the SEP were fabricated at the School of Oceanographic Studies, Jadavpur University. Galvanized iron (GI) pipes, with graduation marks painted in black and red on a white background (figure A2a and $\mathrm{h}$ ), were used. To avoid inaccuracies in painting in the graduation marks, a basic stencil was used. Since in this part of the world, GI pipes are manufactured in units of $6 \mathrm{~m}$ lengths, two such units, joined by an iron socket, were used to fabricate each of the

Figure A2. The Sundarbans present a remarkably challenging environment for making observations. The high tidal range and the soft, clayey mud make it difficult even to erect a tide pole. These photographs present a glimpse of the conditions under which the SEP was conducted. (a) The Visual Tide Staff (VTS) or tide pole at Kaikhali (M14; figure 4). (b) At low tide, the soft, clayey mud of the Sundarbans is exposed. This photograph is from Ramganga (S6; figure 3) and shows the boat lying on the exposed mudbank at low tide. The VTS can be seen at the extreme right. (c) The two pipes broke at the socket joint at a few stations. This photograph is from Melmelia (GH21; figure 4), where the observers managed to repair the pole and resume observations. (d) Reading the water level at night was made tough by the distance of the pole from the boat. This distance was necessitated by the need to ensure that the zero of the pole was not exposed during the lowest low water level. (e) Observations at Dhanchi. Note the three guy wires attached to the top of the pole. These guy wires were anchored to keep the pole vertical. (f) The omnipresent mud disappears during high tide, with even the mangroves barely standing above the high water level. This photograph is from R. Barchara near Mahendranagar (S5; figure 3). (g) Even jetties barely survive submergence during high tide. This photograph shows an abandoned jetty at Pakhiralay (G18; figure 4). (h) A VTS at the Sabuj Sangha building in Nandakumarpur. Note the iron socket, used to join the two GI pipes, around the $140 \mathrm{~cm}$ mark. (i) The VTS deployed at Dhulibhasani. Note the two black marks near the bottom of the part of the VTS visible in this photograph. The upper one is the socket and the lower one is an iron clamp used to hammer the VTS into the mud. 

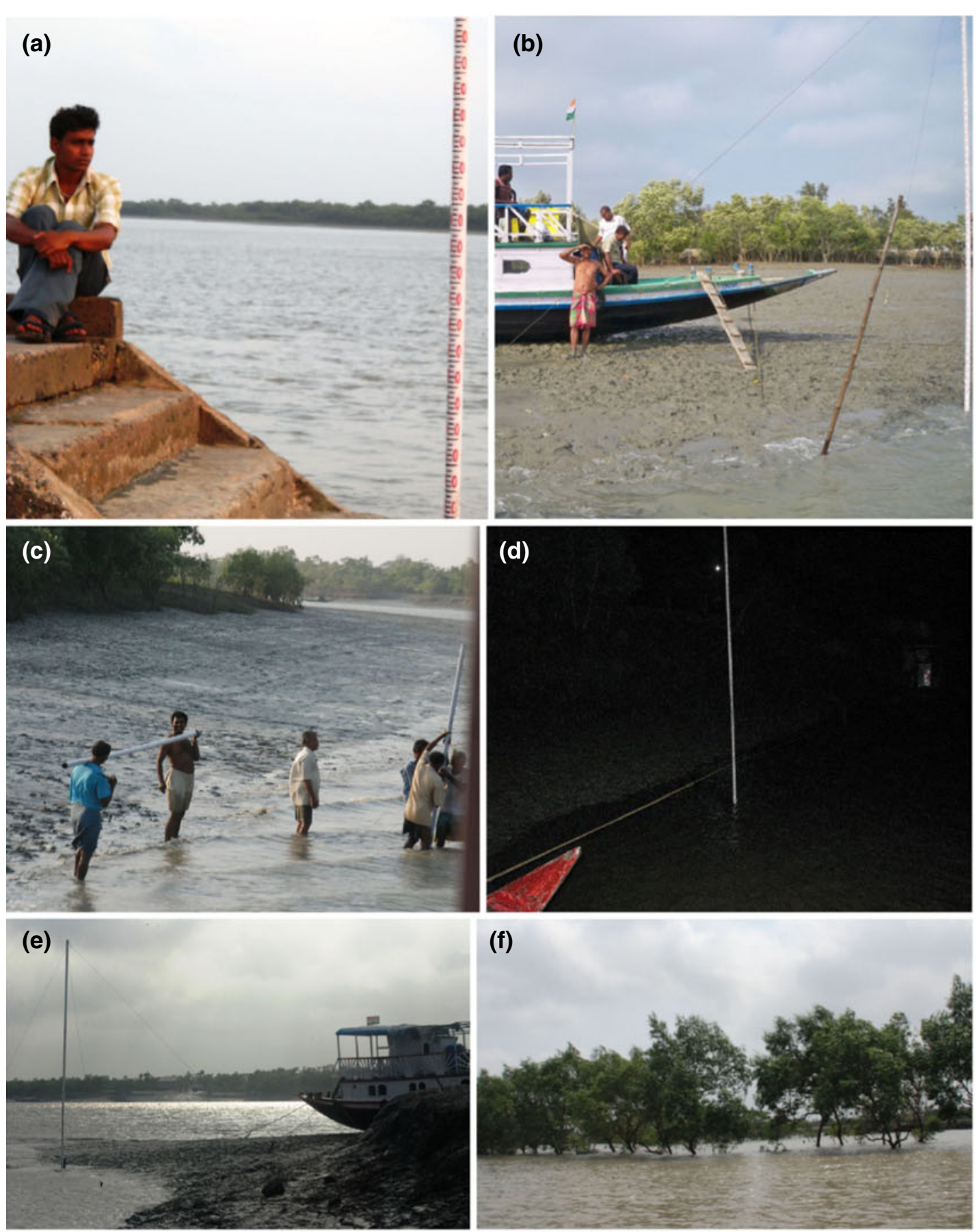

(f)
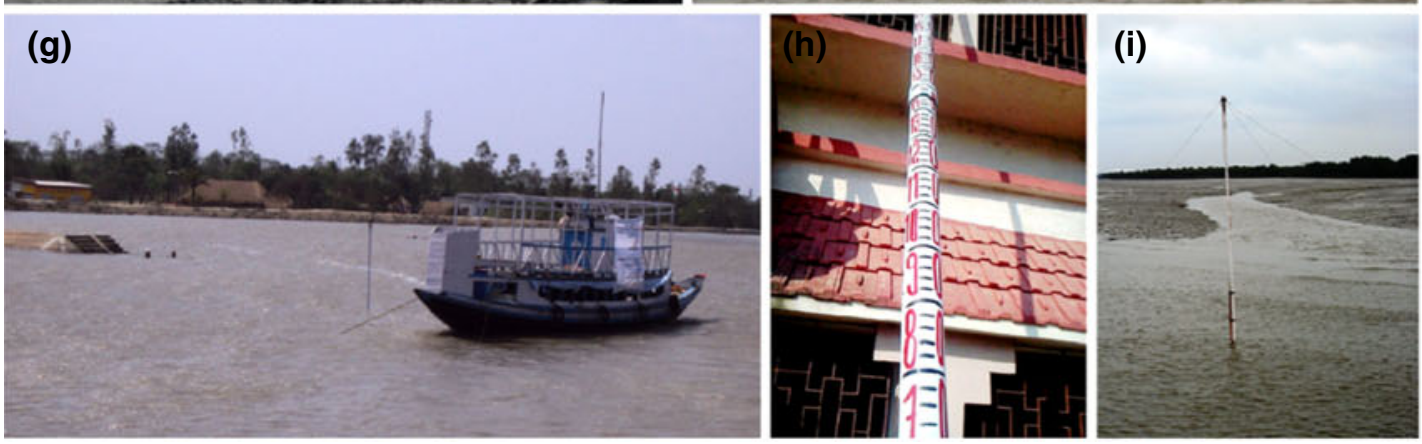
$12 \mathrm{~m}$ long tide poles (figure A2c, $\mathrm{h}$ and i). Optimizing between the readability of the scale, particularly during night (figure A2d), and the weight of the $12 \mathrm{~m}$ long pipe, the pipe diameters had to be restricted between 2 and 3 inches. To ensure that the tide poles remained vertical and firmly fixed to the banks, three iron guy wires were attached to the top of the pole and tied to the banks through suitable anchors (figure A2e, h).

The exposure of the mud (figure $\mathrm{A} 2 \mathrm{~b}, \mathrm{c}$ and e) during low tide is one phase of the tidal cycle in the Sundarbans. The other phase of the tidal cycle submerges the mangrove roots and masks the omnipresent mud (figure A2f) and almost submerges jetties (figure $\mathrm{A} 2 \mathrm{~g}$ ), leaving, only a small part of the $12 \mathrm{~m}$ long pole visible (figure $\mathrm{A} 2 \mathrm{~g}$ ) during high tide.

\section{A2.2 Missed observations}

Most observation teams recorded details of the ambient atmospheric and estuarine conditions, reasons for missed observations, and difficulties faced in taking measurements. These proved to be very helpful while interpreting the data.

The most common reasons for the missed observations (listed in table 4), were the following.

1. The breaking of the upper section of the tide pole from the socket joint due to the combined impact of wind and tide. Repairing of the joint was possible in stations close to local markets. An example is shown in figure A2(c). For stations not having this facility, the upper length was tied tightly with the lower portion and the guy wires suitably adjusted for making the shortened pole vertical. For R28 (Shitalia), this resulted in the shortening of the tide-pole scale to such an extent that both High Water and Low Water levels could no be read.

After refixing the tide pole in this manner, the total length of the lower pole and the time of resumption of the readings were recorded in the observation sheets and Water Levels read off according to the graduation marks in the upper pole. During the data analysis, this length was subtracted from the reported water levels from this time onwards.

At M4 (Bonnie Camp), after re-fixing the pole and proceeding with the measurements in the manner described, the upper pole broke again and all guy wires snapped. Observations here were finally abandoned after 56 hours (see table 2). Fortunately, at most of the stations experiencing this problem, tide poles functioned properly after repair, thus leaving only one stretch of missed observations.
2. Slanting of the tide pole from its vertical position. This problem was corrected by the observers every time it occurred by means of a plumbline, but resulted in some missed observations.

3. The water level receding during low-water events, leaving the tide-pole 'zero' exposed (underranging events). Tide poles were installed during the lowest low water period on the 17th afternoon. Information regarding tidal ranges, particularly in the remote and seaward stations were sparse, however, and as the Spring Tidal Ranges continued to increase, stations like Indrapur, Dhanchi (figure A2e), and Shibganj faced this problem and missed the lowest low water observations.

\section{References}

Acharyya T, Sarma V V S S, Sridevi B, Venkataramana V, Bharathi M D, Naidu S, Kumar B S K, Prasad V R, Bandopadhyay D, Reddy N P C and Kumar M D 2012 Reduced river discharge intensifies phytoplankton bloom in Godavari estuary, India; Mar. Chem. 132-133 $15-22$.

Amante C and Eakins B W 2009 ETOPO1 1 Arc-Minute Global Relief Model: Procedures, data sources and analysis; NOAA Technical Memorandum NESDIS NGDC-24, $19 \mathrm{p}$.

Anonymous 1865 Notice to Mariners: Sailing instructions for entering the River Mutlah from the sea; In: The London Gazette, June 17, p. 2139.

Attri S D and Tyagi Ajit 2010 Climate Profile of India; Met. Monograph No. Environment Meteorology - 01/ 2010. India Meteorological Department, Ministry of Earth Sciences, Government of India, 129p.

Bannerjee A 1998 Environment, population and human settlement of Sundarban Delta; Concept Publishing, 424p.

Basu A K and Ghosh B B 1970 Observations on diurnal variations in some selected stretch of the Hooghly estuary (India); Aquatic Sci. 32 271-283.

Bayly C A 1985 Inland port cities in north India: Calcutta and the Gangetic Plains, 1780-1900; In: The rise and growth of the colonial port cities in Asia (ed.) Basu D K (Berkeley: University Press of America), pp. 13-17.

Bell C, Vassie J M and Woodworth P L 1998 POL/PSMSL Tidal Analysis Software Kit 2000 (TASK-2000). Permanent Service for Mean Sea Level; CCMS Proudman Oceanographic Laboratory, Bidston Observatory, Birkenhead, UK, 21p.

Beveridge H 1897 Akbarnama Vol I; Translation of the original work by A Fazl (in Persian), Asiatic Society of Bengal, Calcutta.

Boon J D and Byrne R J 1981 On basin hypsometry and the morphodynamic response of coastal inlet systems; Mar. Geol. $4027-48$.

Bose B B 1956 Observations on the hydrology of the Hooghly estuary; Indian J. Fisheries 3 101-118.

Bouillon S, Frankignoulle M, Dehairs F, Verlimirov B, Eiler A, Etcheber H, Abril G and Borges A V 2003 Inorganic and organic carbon biogeochemistry in the Gautami Godavari estuary (Andhra Pradesh, India) during pre-monsoon: The local impact of extensive mangrove forests; Global Biogeochemical Cycles 17(4) 114, doi: 10.1029/2002GB002026. 
Chakrabarti R 2009 Local people and the global tiger: An environmental history of the sundarbans; Global Environment n3 72-95, http://www.globalenvironment.it/.

Chanson H 2001 Flow field in a tidal bore: A physical model; In: Proc. 29th IAHR Congress. Beijing, China, Theme E (ed.) G Li; Tsinghua University Press, Beijing (CDROM, Tsinghua University Press), pp. 365-373.

Chugh R S 1961 Tides in Hooghly River; Hydrol. Sci. J. 6(2) $10-26$.

Das M K and Samanta S 2006 Application of an index of biotic integrity (IBI) to fish assemblage of the tropical Hooghly estuary; Indian J. Fish. 53(1) 47-57.

De R N 1990 The Sundarbans; Oxford University Press, Delhi, 49p.

Dinesh Kumar P K 2001 Monthly mean sea level variations at Cochin, southwest coast of India; Int. J. Ecol. Env. Sci. 27 209-214.

Dinesh Kumar P K, Gopinath G, Laluraj C M, Seralathan P and Mitra D 2007 Change detection studies of Sagar Island, India, using Indian Remote Sensing Satellite 1C Linear Imaging Self-Scan Sensor III Data; Int. J. Coastal Res. 23(6) 1498-1502.

Dronkers J 1986 Tidal asymmetry and estuarine morphology; Netherlands J. Sea Res. 20(2/3) 117-131.

Dutta N, Malhotra J C and Bose B B 1954 Hydrology and seasonal fluctuations of the plankton in the Hooghly estuary; In: Symposium on Marine and Freshwater Plankton in the Indo-Pacific Fish Council, Bangkok, pp. 35-47.

Foreman M G G 2004 Manual for tidal heights analysis and prediction; Pacific Marine Sciences Report 77-10 Revised October 2004, Institute of Ocean Sciences, Patricia Bay, Victoria, British Columbia, 58p.

Fortunato A and Oliveira A 2005 Influence of intertidal flats on tidal asymmetry; J. Coastal Res. 21(5) 10621067.

Friedrichs T C and Aubrey D G 1988 Non-linear tidal distortion in shallow well mixed estuaries: A synthesis; Estuarine Coast. Shelf Sci. 27 521-545.

Friedrichs T C and Madsen O S 1992 Nonlinear diffusion of the tidal signal in frictionally dominated embayments; J. Geophys. Res. 97 5637-5650.

Ganguly D, Mukhopadhyay A, Pandey R and Mitra D 2006 Geomorphic study of Sundarbans Deltaic Estuary; J. Indian Soc. Rem. Sens. 34(4) 431-435.

Ganguly D, Mukhopadhyay A, Pandey R and Mitra D 2007 Study of coastal water pollution in Sundarbans; ICFAI J. Earth Sci. 1(3) 55-64.

Ghosh Amitava 2004 The Hungry Tide; Ravi Dayal Publisher, Delhi, 433p; Achintyarup Roy 2009 Bhatir Desh. Bengali translation. Ananda Publishers, 377p.

Gole C V and Vaidyaraman P P 1967 Salinity distribution and effect of fresh water flows in the river Hooghly; In: Proc. Tenth Congress of Coastal Engineering Tokyo 2 1412-1434.

Guha Bakshi D N, Sanyal P and Naskar K R (eds) 1999 Sundarban Mangals; Naya Prokash, Kolkata, 771p. (ISBN 81-85421-55-2).

Heritage Trevor 2006 Poole Harbour and its tides; http:// www.shrimperowners.org/sitefiles/Poole\%20Tides.pdf.

India Meteorological Department 2009 Severe Cyclonic Storm, AILA: A Preliminary Report; Regional Specialized Meteorological Centre-Tropical Cyclones, New Delhi, 26p.

IWAI 2011 Indo-Bangladesh Protocol 01 April 2011; Inland Waterways Authority of India, Ministry of Shipping, Govt. of India, http://iwai.gov.in/piwtt.htm.

Jayappa K S, Jayappa K S, Mitra D and Mishra A K 2006 Coastal geomorphological and land-use and land cover study of Sagar Island, Bay of Bengal (India) using remotely sensed data; Int. J. Rem. Sens. 27(17) 3671-3682.

Jha R, Ghosh N C and Chakraborty B 1999 Flow computation of river estuaries using finite element model; Technical Note CS(AR) 21/96-97, National Institute of Hydrography, Roorkee, 78p.

Joseph A, Mehra P, Prabhudesai R G, Sivadas T K, Balachandran K K, Vijaykumar K, Revichandran C, Agarvadekar Y, Francis R and Martin G D 2009 Observed thermohaline structure and cooling of Kochi backwaters and adjoining southeastern Arabian Sea; Curr. Sci. 96(3) $364-375$.

Kyd James 1829 Tables exhibiting a daily register of the tides in the River Hooghly at Calcutta from 1805 to 1828 with observations on the results thus obtained; Asiatic Researches XVIII pt I, 259 (Centenary Review of the Asiatic Society of Bengal from 1784-1883. Appendix D, p. 152).

Lanzoni S and Seminara G 1998 On tide propagation in convergent estuaries; J. Geophys. Res. 103(C13) 30,79330,812 .

Lanzoni S and Seminara G 2002 Long-term evolution and morphodynamic equilibrium of tidal channels; $J$. Geophys. Res. 107(C1) 1-13.

Majumdar S C 1942 Rivers of the Bengal Delta; Calcutta University Readership Lectures, Calcutta University, 124p.

Mandal A K 2003 The Sundarbans of India: A development analysis; Indus Publishing, 260p, ISBN 8173871434.

Mandal S, Ray S and Ghosh P B 2009 Modelling of the contribution of dissolved inorganic nitrogen (DIN) from litter fall of adjacent mangrove forest to Hooghly-Matla estuary, India; Ecological Modelling 220(21) 2988-3000.

Manna S, Chaudhuri K, Bhattacharyya S and Bhattacharyya M 2010 Dynamics of Sundarban estuarine ecosystem: Eutrophication induced threat to mangroves; Saline Systems 6 8, http://www. salinesystems.org/content/6/1/8.

Martin G D, Vijay J G, Laluraj C M, Madhu N V, Joseph T, Nair M, Gupta G V M and Balachandran K K 2008 Freshwater influence on nutrient stoichiometry in a tropical estuary, southwest coast of India; Appl. Ecol. Environ. Res. 6(1) 57-64, http://www.ecology.uni-corvinus.hu, ISSN 15891623.

Mukherjee D, Banerjee A and Sen G K 2006 Physicochemical properties of water and fish availability at the Muriganga Estuary adjoining Bakkhali Region of western Indian Sundarbans; Environ. Ecol. 24(2) 385-388.

Mukherjee D and Sen G K 2008 Mangrove filtration of nutrients in and around the Muriganga and Subarnarekha Estuary on the east coast of India; Pollut. Res. 27(4) 659-663.

Mukherjee D, Banerjee A and Sen G K 2008 Present ecological status at estuarine ecosystem of Sundarbans and Digha in relation to fish catch; Int. J. Ecol. Environ. Conservat. 14(2-3) 387-392.

Mukherjee D, Das M and Sen G K 2010 Water quality assessment in the mangrove ecosystem of Indian Sundarbans; Asian J. Microbiol. Biotechnol. Environ. Sci. 12(3) $561-563$

Mukhopadhyay S K, Biswas H, De T K, Sen S and Jana T K 2002 Seasonal effects on the air-water carbon dioxide exchange in the Hooghly estuary, NE coast of Bay of Bengal, India; J. Environ. Monit. 4 549-552.

Murty T S and Henry R F 1983 Tides in the Bay of Bengal; J. Geophys. Res. 88 6069-6076.

Nandy A C, Bagchi M M and Majumder S K 1983 Ecological changes in the Hooghly estuary due to water release 
from Farakka Barrage; Mahasagar - Bull. National Inst. Oceanogr. 16(2) 209-220.

Naskar K R 2003 Manual of Indian Sunderbans; Daya Publishing House, Delhi, 221p, ISBN 81-7035-303-3.

Naskar K R and Mandal R 1999 Ecology and biodiversity of Indian Mangroves: Parts I \& II; Daya Publishing House, Delhi, 754p, ISBN 81-7035-190-1.

NATMO 2000 Map of 24 Parganas (South), First edn, Scale 1:250,000; National Atlas \& Thematic Mapping Organization, Government of India.

National Geospatial Intelligence Agency 2005 Prostar sailing directions, India and Bay of Bengal en route; Publication 173. Revised and corrected through NTM 33/05 (13 August 2005), 8th edn.

NOAA 2000 Tide and Current Glossary; U.S. Department of Commerce, NOAA, National Ocean Service, Centre for Operational Oceanographic Products and Services, 29p. co-ops.nos.noaa.gov/publications/glossary2.pdf

NTC Glossary 2010 Tidal Terminology; National Tidal Centre, Australian Bureau of Meteorology, PO Box 421, Kent Town, SA 5071, 41p, http://www.bom.gov.au/ oceanography/projects/ntc/ntc.shtml.

Oag T M 1939 Report on the River Hooghly and its headwaters, Commissioners for the Port of Calcutta.

Papa F, Durand F, Rossow W B, Rahman A and Bala S K 2010 Satellite altimeter-derived monthly discharge of the Ganga-Brahmaputra River and its seasonal to interannual variations from 1993 to 2008; J. Geophys. Res. 115 C12013, doi: 10.1029/2009JC006075.

Parua P K 2010 The Ganga. Water Use in the Indian Subcontinent; Water Science and Technology Library. Springer, 64, 391p, ISBN 978-90-481-3102-0, e-ISBN 978-90-481-3103-7, doi: 10.1007/978-90-481-3103-7.

Pingree R D and Griffiths D K 1979 Sand transport paths around the British Isles resulting from M2 and M4 tidal interactions; J. Mar. Biol. Ass. 59 497-513.

Pugh D T 1987 Tides, Surges and Mean Sea-Level; Wiley, New York, 472p.

Quasim S Z and Gopinathan C K 1969 Tidal cycle and the environmental features of Cochin backwater (A tropical estuary); Proc. Indian Acad. Sci. 69 336-348.

Rao R M 1969 Studies on the prawn fisheries of the Hooghly estuarine system; Proc. Nat. Inst. Sci. India 35B 1-27.

Ray A 1990 The Calcutta port; In: The present and future. Calcutta: The living city (ed.) Chaudhuri S (Calcutta: Oxford University Press) 2 123-127.

Roy H K 1949a Some potamological aspects of the river Hooghly in relation to Calcutta water supply; Science and Culture 14320.

Roy N R 1949b Manikchandra Rajar Gan, folk song of Bengal (Bhatiali); In: Banglar Itihas; Book Emporium, Kolkata, p. 104.

Roy H K 1955 Plankton ecology of the river Hooghly in Palta, West Bengal; Ecology 36169.

Sadhuram Y, Sarma V V, Ramana Murthy T V and Prabhakara Rao B 2005 Seasonal variability of physicochemical characteristics of the Haldia channel of Hooghly estuary, India; J. Earth Syst. Sci. 114 37-49.

Saha S B, Ghosh B B and Gopalkrishna V 1971 Plankton of the Hooghly estuary with special reference to salinity and temperature; In: Symposium on Indian Ocean and Adjacent Seas, the Marine Biological Association of India, Cochin (12-18 January).

Sanyal P 1983 Mangrove tiger land, the Sundarbans of India; Tigerpaper 10(3) 1-4.

Sarkar K L 2011 Sundarbaner Itihaas (in Bengali); Rupkatha Prakashan, 184p.

Sarma V V S S, Gupta S N M, Babu P V R, Acharya T, Harikrishnachari N, Vishnuvardhan K, Rao N S, Reddy
N P C, Sarma V V, Sadhuram Y, Murty T V R and Kumar M D 2009 Influence of river discharge on plankton metabolic rates in the tropical monsoon driven Godavari estuary, India; Estuarine Coast. Shelf Sci. 85(4) 515-524.

Sarma V V S S, Prasad V R, Kumar B S K, Rajeev K, Devi B M M, Reddy N P C, Sarma V V and Dileepkumar M 2010 Intra-annual variability in nutrients in the Godavari estuary, India; Continent. Shelf Res. 30(19) 2005-2014.

Sarma V V S S, Kumar N A, Prasad V R, Venkataramana V, Appalanaidu S, Sridevi B, Kumar B S K, Bharati M D, Subbaiah C V, Acharyya T, Rao G D, Viswanadham R, Gawade L, Manjary D T, Kumar P P, Rajeev K, Reddy N P C, Sarma V V, Kumar M D, Sadhuram Y and Murty T V R 2011 High $\mathrm{CO}_{2}$ emissions from the tropical Godavari estuary (India) associated with monsoon river discharges; Geophys. Res. Lett. 38(8) L08601.

Seidensticker J and Hai M A 1983 The Sundarbans Wildlife Management Plan. Conservation in the Bangladesh Coastal Zone. IUCN, Gland, 120p.

Shetty H P C, Saha S B and Ghosh B B 1961 Observations on the distribution and fluctuations of plankton in the Hooghly-Matlah estuarine systems with notes on their relation to commercial fish landings; Indian J. Fisheries $8326-363$.

Shetye S R and Gouveia A D 1992 On the role of geometry of cross-section in generating flood dominance in shallow estuaries; Estuarine Coast. Shelf Sci. 35 113-126.

Shetye S R, Gouveia A D, Singbal S Y, Naik C G, Sundar D, Michael G S and Nampoothiri G 1995 Propagation of tides in the Mandovi-Zuari estuarine network; Proc. Indian Acad. Sci. (Earth Planet. Sci.) $104667-682$.

Shetye S R, Gouveia A D and Shankar D et al. 1996 Hydrography and circulation in the western Bay of Bengal during the northeast monsoon; J. Geophys. Res. 101 14011-14025.

Shetye S R, Dileep Kumar M and Shankar D (eds) 2007 The Mandovi and Zuari estuaries, National Institute of Oceanography, Goa, India, 145p, available at http://drs.nio.org/drs/handle/2264/1032.

Sinha M, Mukhopadhyay M K, Mitra P M, Bagchi M M and Karmakar H C 1996 Impact of Farakka Barrage on the hydrology and fishery of Hooghly Estuary; Estuaries 19(3) 710-722.

Song D, Wang X H, Kiss A E and Bao X 2011 The contribution to tidal asymmetry by different combinations of tidal constituents; J. Geophys. Res. 116 C12007, doi: 10.1029/2011JC007270.

Speer P E 1984 Tidal Distortion in Shallow Estuaries; Ph.D. Thesis, MIT/WHOI, WHOI-84-25, Woods Hole Oceanographic Institution, 210p.

Speer P E and Aubrey D G 1985 A study of non-linear tidal propagation in shallow inlet/estuarine systems, part II - Theory; Estuarine Coast. Shelf Sci. 21 $207-224$.

Speer P E, Aubrey D G and Friedrichs C T 1991 Nonlinear hydrodynamics of shallow tidal inlet/bay systems; In: Tidal Hydrodynamics (ed.) Parker B B (New York: John Wiley), pp. 321-329.

Srinivas C, Revichandran P A, Maheswaran T T, Mohammad Ashraf and Nuncio Murukesh 2003 Propagation of tides in the Cochin estuarine system, southwest coast of India; Indian J. Marine Sci. 32(I) 14-24.

Sundar D and Shetye S R 2005 Tides in the Mandovi and Zuari estuaries, Goa, west coast of India; J. Earth Syst. Sci. 114(5) 493-503.

Survey of India 1967-1969 Map Nos. 79C/1 and 79C/2, Districts 24 Parganas and Medinipur, 3rd (1st metric) edn, Scale 1:50000. 
Survey of India 1977 Controlled Aerial Photomosaic, 47 photos, 5 runs, Scale 1:50000.

Tan Tai-Yong 2007 Port cities and hinterlands: A comparative study of Singapore and Calcutta; Political Geogr. 26 851-865.

UNEP WCMC 1987 (updated May 2011) Sundarbans National Park, West Bengal, India; UNEP World Conservation Monitoring Centre, 11p.

United Kingdom Hydrographic Office 2011 Tide table Format: Events per day and event selection; 3rd Tidal and
Water Level Working Group Meeting, 5-7 April 2011, Jeju Island, South Korea, 10p.

United Kingdom Hydrographic Office 2012 Frequently Asked Questions on EasyTide; http://easytide.ukho.gov.uk/ EASYTIDE/EasyTide/Support/faq.aspx.

Vijith V, Sundar D and Shetye S R 2009 Time-dependence of salinity in monsoonal estuaries; Estuarine Coast. Shelf Sci. 85(4) 601-608.

Wikipedia 2012 Cyclone Aila; http://en.wikipedia.org/ wiki/Cyclone Aila. 